\title{
Efficiency of Respiratory Protective Equipment in the SARS-CoV-2 Pandemic
}

\author{
K. I. Lukanina ${ }^{a, *}$, A. K. Budyka ${ }^{b}$, I. E. Rebrov ${ }^{c}$, K. G. Antipova ${ }^{a}$, S. N. Malakhov ${ }^{a}$, A. D. Shepelev ${ }^{a}$, \\ T. E. Grigoriev ${ }^{a}$, V. A. Yamshchikov ${ }^{c}$, and S. N. Chvalun ${ }^{a}$ \\ ${ }^{a}$ National Research Center Kurchatov Institute, Moscow, 123182 Russia \\ ${ }^{b}$ National Research Nuclear University MEPhI, Moscow, 115409 Russia \\ ${ }^{c}$ Institute of Electrophysics and Electric Power, Russian Academy of Sciences, St. Petersburg, 191186 Russia \\ *e-mail: lukanina_ki@nrcki.ru
}

Received October 26, 2020; revised December 21, 2020; accepted December 24, 2020

\begin{abstract}
Respiratory protective equipment (RPE) is in high demand during epidemics and pandemics. The SARS-CoV-2 pandemic has demonstrated that the global industry had insufficient capacity for providing people with high-efficiency respirators. In this context, it is important to assess the protective properties of equipment designed to prevent the spread of infections. In this review, the hydrodynamic and filtering characteristics of modern RPE types present in the market, as well as their consumer performance, are analyzed taking into account the properties of virus-bearing aerosols. Approaches to developing novel, more efficient fiber-based RPE are proposed.
\end{abstract}

DOI: $10.1134 / \mathrm{S} 2635167621010080$

\section{CONTENTS}

Introduction

1. Types of RPE

2. Review of respirators manufactured in Russia

3. Assessment of RPE efficiency

4. Propagation of SARS-CoV-2 in air

5. Theoretical basis of bioaerosol filtration

6. Methods of manufacturing filtering materials

7. Current developments in RPE production

Conclusions

\section{INTRODUCTION}

Occasional pandemic disease outbreaks, such as influenza in 1918 or H1N1, represent a major hazard for global economical and demographical stability [1]. The viral pandemic of 2020 has made obvious the urgency of issues related to respiratory tract protection from aerosol particles. According to the data of John Hopkins University, more than 60 million people were infected with SARS-CoV-2 from January to November 2020, and more than 1.4 million died [2]. Disease outbreaks caused by pathogenic agents with high diffusion rates, such as SARS-CoV-2, increase the level of exposure to biological hazards for medical professionals. Under these conditions, healthcare workers are obliged to utilize respiratory protective equipment (RPE). During a respiratory disease pandemic, RPE availability can be strongly limited because of unusu- ally high demand resulting in shortage of raw materials [3] and suboptimal logistic flows between manufacturers and consumers.

Ebola, MERS, SARS, or SARS-CoV-2, SARS$\mathrm{CoV}-1$ are examples of zoonotic infectious diseases transmitted among humans via aerosol and contact pathways. COVID-19 virions have an estimated size of from 60 to $140 \mathrm{~nm}$. On scanning electron microscopy images, the spherical viral capsids feature 9- to 12-nmlong spikes that resemble a crown, hence the family name, Coronaviridae [4]. For comparison, the viruses causing severe acute respiratory syndrome (SARS) and Middle East respiratory syndrome (MERS) are approximately $80 \mathrm{~nm}$ and $127 \pm 9 \mathrm{~nm}$ in diameter with 16- to 21-nm long spikes on their surface.

SARS, MERS, and COVID-19 agents are RNA viruses of the family Orthomyxoviridae. In some respects, coronaviruses are similar to influenza viruses (Orthomyxoviridae); e.g., they both possess RNA genomes [3]. Viruses are transported by aerosol particles that can be carried over long distances, as well as spread over entire volume of enclosed spaces.

Aerosols containing SARS-CoV do not differ in their physical properties from other bioaerosols produced by complete or partial evaporation of liquid dispersed phase. Depending on the size of the particle resulting from evaporation of the primary droplet, it will either enlarge due to coagulation or remain stable, representing a conglomerate with a high concentration of viruses. 
The final size of bioaerosol particles corresponds to the size of the most stable particles typical for the given conditions of dispersion medium (e.g., temperature, pressure, humidity, and dustiness).

Bioaerosol capturing by concentrating the dispersed phase using filtration relies on the same physical principles (mechanisms) that underlie the operation of filters for other aerosols.

The importance of having sufficient RPE supply and the level of awareness among medical workers about their proper use in healthcare settings became obvious during the still ongoing COVID-19 outbreak, since a large proportion of medical professionals have been infected. Considering the shortage of respirators and protective masks, the US Center for Disease Control and Prevention recommended a procedure to decontaminate disposable RPE units. The corresponding declaration notes that the use of decontaminated aerosol protective equipment should be a part of the strategy to ensure the protection of healthcare personnel during the pandemic. To maintain the effectiveness of RPE after decontamination, the procedure is based on the use of hydrogen peroxide, UV irradiation, and steam treatment. At the same time, procedures that lead to degradation of protective materials and reduce the effectiveness of aerosol capture are not recommended [3].

During the 2020 pandemic, most hotspots were supplied mainly with disposable, non-face-fitting medical masks. They are primarily designed to decrease the spread of respiratory infections, in particular, to provide general respiratory protection from large droplets produced by coughing or sneezing. Despite appearances, medical masks and respirators are fundamentally different. While respirators are designed to protect the wearer's respiratory organs from exposure to external aerosols, masks serve to decrease the likelihood of the wearer infecting surrounding people should he or she be a carrier of an infection. Note that respirators without an exhalation valve also prevent the respirator wearer from infecting others.

Respirator materials must have high particle trapping efficiency over a wide range of sizes and, at the same time, low breathing resistance. Furthermore, the most important feature of a respirator is a secure face line (sealing), without which the high effectiveness of the material is of no practical use. Finally, its cost must be commensurate with the practical benefits of its use over the period of exploitation.

\section{TYPES OF RPE}

In European countries, the most common types of RPE are type I (for patients) and type II and IIR (for medical workers in the operating room or during any contact with patients in a hospital setting). The princi- pal difference between these type is the level of protection [3].

Another class of RPE includes filtering facepiece (FFP) respirators. They are tight-fitting, disposable protective equipment designed to trap aerosol particles less than $5 \mu \mathrm{m}$ in diameter. Filtering respirators are labeled depending on their properties and national standards. For instance, the FFP2 standard describes respirators that decrease the concentration of particles in the inhaled air by at least $94 \%$, while FFP3 respirators have at least $99 \%$ efficiency. According to recommendations of the WHO, COVID-19 patients should utilize FFP2 respirators. In addition, the use of similar RPE is recommended during aerosol-producing procedures: cardiopulmonary resuscitation, tracheal intubation or aspiration, tracheotomy, bronchoscopy, or noninvasive ventilation. National regulatory standards are similar around the world, and recommendations usually concern a specific RPE class or its foreign equivalent models. For instance, the FFP2 class includes respirators N95 (United States), KN95 (China), P2 (Australia/New Zealand), DS (Japan), and some others. However, recent systematic investigations did not detect significant differences in the protective efficiency of N95 respirators and medical masks for prophylaxis of influenza. Apparently, this was due to insufficient sealing of N95 respirators; therefore, they were recommended for use under conditions of low-level infection hazard [3, 5-7].

Since FFP masks are tested using the most penetrating aerosol particles and at elevated filtration rates (i.e., under most unfavorable conditions), their actual efficiency is usually higher than the level determined during the tests. The protective capacity of respirators strongly depends on their faceline security, which means that healthcare workers require individually selected RPE of an appropriate model and size [3].

Under special circumstances, disposable FFP masks can be replaced by alternative respirators not normally used in medical facilities, such as elastomeric respirators or forced-air protective equipment designed for highly aggressive air media. Elastomeric respirators possess replacement filter blocks and therefore are reusable. RPE units of the second group are additionally equipped with a compressor system of filter pumping, which limits their applicability.

\section{REVIEW OF RESPIRATORS MANUFACTURED IN RUSSIA}

In the Soviet Union, development and production of respirators were mainly related to the maintenance of the atomic project. Respirators were manufactured from nonwoven fibrous materials (Petryanov filters) obtained from polymer solutions using the electrospinning technique. The most widespread Lepestok respirators were produced from chlorinated polyvinyl chloride (CPVC) materials: FPP-70-0.2, FPP-70-0.5 
Table 1. Performance characteristics of respirators produced in Russia

\begin{tabular}{c|c|c|l}
\hline Model & $\begin{array}{c}\text { Resistance to respira- } \\
\text { tion at } 30 \mathrm{~L} / \mathrm{min}, \mathrm{Pa}\end{array}$ & $\begin{array}{c}\text { Efficiency by particles } \\
\text { of } 0.1-0.2 \mu \mathrm{m}, \%\end{array}$ & \multicolumn{1}{|c}{ Range of protection } \\
\hline Lepestok-200 & $30.4 \pm 3.9$ & 99.9 & $\begin{array}{l}\text { Finely dispersed aerosols with concentrations of up to } \\
\text { 200 MAC }\end{array}$ \\
\hline Lepestok-40 & $9.8 \pm 2.0$ & 99.5 & $\begin{array}{l}\text { Finely dispersed aerosols with concentrations of up to } \\
\text { 40 MAC and coarsely dispersed aerosols with concentra- } \\
\text { tions of up to 200 MAC }\end{array}$ \\
\hline Lepestok-5 & $4.9 \pm 1.0$ & 96.0 & $\begin{array}{l}\text { Finely dispersed aerosols with concentrations of up to } \\
\text { 5 MAC and coarsely dispersed aerosols with concentra- } \\
\text { tions of up to 200 MAC }\end{array}$ \\
\hline
\end{tabular}

(with average fiber diameter of $7 \mu \mathrm{m}$ ), and FPP-15-1.5 $(1.5 \mu \mathrm{m})$. The standard resistance of these materials (pressure drop at a flow velocity of $1 \mathrm{~cm} / \mathrm{s}$ ) constituted $\sim 2,5$, and $15 \mathrm{~Pa} \mathrm{~cm}^{-1} \mathrm{~s}^{-1}$, respectively. The Karpov Institute of Physical Chemistry in collaboration with the Institute of Biophysics used them to develop three types of respirators: Lepestok-200, Lepestok-40, and Lepestok-5 (Table 1). The respirators are produced in accordance with specifications GOST 12.4.028-76 SSBT.

The principal element of the respirator is the cap, which acts both as a filter (with a working surface of $240 \mathrm{~cm}^{2}$ ) and as a half-mask, while framing is provided by both the spacer and the glued outer gauze. The peripheral ring of the cap, where the rubber cord and the aluminum plate are attached, serves as a seal ensuring a tight fit of the half mask. For better sealing, the inner surface of the filtering material is not covered with gauze. This design very nearly prevents the intake of unfiltered air and allows the respirator to be used by people with different facial structures. These respirators are one-size; they do not limit the field of vision or muffle the tones of spoken speech. The weight of Lepestok respirators is $\sim 10 \mathrm{~g}$.

Over the entire manufacturing period, more than 5 billion Lepestok respirators were produced. The Kimry Gorky Factory is still producing these respirators with minor modifications.

In spite of their obvious advantages (high efficiency, decades-proven reliability, and low cost), these respirators also have certain shortcomings. In particular, they need to be assembled prior to use. The wearer should tighten the regulatory elastic band to obtain the required bowl-like shape, put the respirator on by tying the straps on their head, and crimp the aluminum plate on the bridge of their nose. It should be noted that currently these respirators are proposed in the assembled form.

To date, CPVC, as well as filtering materials made thereof, are no longer produced in Russia; they have been replaced by other materials, e.g. chlorinated polyethylene or fabrics obtained using the melt blowing process.

NANOBIOTECHNOLOGY REPORTS Vol.16 No.1
Various manufacturers produce numerous kinds of ready-to-use RPE similar to Lepestok respirators: e.g., Spiro and Lotos (Kimry Gorky Factory) [8] or Alina, Yulia, and Neva (Sevzappromenergo) [9]. These products conform to three classes of protection: FFP1, FFP2, and FFP3 (GOST 12.4.191-99), and have all necessary Russian certificates of compliance. Respirators are available in different versions, with and without the exhalation valve. Reusable respirators usually can be subjected to disinfection for protection from pathogenic microorganisms. For instance, the manufacturer recommends disinfecting Alina respirators $106 / 116 / 206 / 216 / 316$ by soaking in special peracetic acid-based solution with subsequent washing with water and drying under normal conditions [10]. The performance characteristics of modern respirators present in the market are shown in Table 2 [11].

The major shortcoming of high-efficiency respirators is that breathing generates a high pressure drop on the filter material $\left(20-40 \mathrm{~Pa} \mathrm{~cm}^{-1} \mathrm{~s}^{-1}\right)$. Due to selfsimilarity of the flow, the pressure drop is directly proportional to the linear velocity of the air flow. For instance, for Lepestok and Alina respirators, as well as similar RPE, filtration velocity varies within a range of up to $10 \mathrm{~cm} / \mathrm{s}$, which means that the pressure drop can reach 200-400 Pa. The users of high-efficiency RPE can experience considerable discomfort when wearing them for a long time, as well as during increased physical activity.

Thus, decreasing aerodynamic resistance to respiration while maintaining the efficiency of filtering represents a topical scientific and technical problem that needs to be solved to create RPE with improved performance characteristics. Some of the approaches used to address this issue will be discussed in Section 5.

\section{ASSESSMENT OF RPE EFFICIENCY}

Certainly, the key parameter that determines the efficiency of RPE is the maintenance of secure fitting (sealing) along the face line in the course of use. The efficiency of respirators and their air-tightness for inhalation and exhalation are evaluated using the fit 
Table 2. Performance characteristics of modern respirators present in the market

\begin{tabular}{|c|c|c|c|c|c|c|}
\hline \multirow{3}{*}{ No. } & \multirow{3}{*}{ Respirator brand } & \multirow{3}{*}{$\begin{array}{l}\text { Pressure } \\
\text { drop, } \mathrm{Pa}\end{array}$} & \multicolumn{4}{|c|}{$\begin{array}{l}\text { Penetration coefficient }(\%) \\
\text { depending on the particle size, } \mu \mathrm{m}\end{array}$} \\
\hline & & & 0.175 & 0.35 & 0.175 & 0.35 \\
\hline & & & \multicolumn{2}{|c|}{ first measurement } & \multicolumn{2}{|c|}{ second measurement } \\
\hline 1 & 3M 8101 FFP1 (Vostok servis) & 48 & 10.30 & 4.10 & & \\
\hline 2 & $\begin{array}{l}\text { Kleen Guard No. 10SHN95 FFP1 CE } 0194 \text { EN } \\
\text { 149:2001 } 64240 \text { (Kimberli-Clark) }\end{array}$ & 84 & 0.68 & 0.12 & 0.49 & 0.10 \\
\hline 3 & SUP AIR 23101 FFP10 EN 149:2001 CE 0086 & 92 & 1.58 & 0.33 & & \\
\hline 4 & Feniks F-1/5 GOST R 12.4 191-99 FP RC 2 AE 44 & 65 & 30.10 & 15.60 & & \\
\hline 5 & HY 8610 FFP1 TN 149:2001 CE 0086 & 65 & 10.60 & 3.10 & & \\
\hline 6.1 & Alina-P GOST R 12.4 191- 99 & 104 & 0.46 & 0.07 & 0.70 & 0.15 \\
\hline 6.2 & Alina-200 GOST R 12.4 191-99 & 110 & 1.38 & 0.36 & 1.41 & 0.34 \\
\hline 7 & $\mathrm{U}-2 \mathrm{k}$ & 33 & 94.20 & 90.70 & & \\
\hline 8 & Technical mask STAYER ECO 1110-H10 & 33 & 88.30 & 81.90 & & \\
\hline 9 & FFP2 823 EN 149:2001 CE 0086 & 110 & 1.00 & 0.16 & 1.00 & 0.16 \\
\hline 10 & DM 0401 FFP1 EN 149:2001 CE 0121 & 114 & 0.15 & $<0.05$ (to 0.275$)$ & 0.18 & $<0.06$ \\
\hline 11 & 3M 9322 EN 149:2001 FFP2 CE 0086 & 81 & $<0.13$ & $0.04($ to 0.275$)$ & 0.14 & $<0.05$ \\
\hline 12 & Alina-AV GOST R 12.4 191-99 & 95 & 0.83 & 0.10 & & \\
\hline 13 & Horizontal Fold-Flat Respirator & 111 & 0.23 & 0.05 (to 0.275$)$ & & \\
\hline 14 & SUR AIR 23105 FFP10 EN 149:2001 CE 0086 & 77 & 1.19 & 0.20 & 1.28 & 0.24 \\
\hline 15 & Horizontal Fold-Flat Respirator & 116 & 0.11 & $0.28($ to 0.275$)$ & & \\
\hline 16.1 & SPIROTEK ULTRA SH3100 FFP 1 & 90 & 1.30 & 0.26 & & \\
\hline 16.2 & SPIROTEK ULTRA SH3100 FFP 2 & 106 & 0.24 & 0.02 & 0.30 & 0.07 \\
\hline 16.3 & SPIROTEK ULTRA SH3100 FFP 3 & 131 & $<0.01$ & $<0.002$ & & \\
\hline 17 & Alvateks & 101 & 1.42 & 0.25 & 2.87 & $0.70<$ \\
\hline 18 & $\begin{array}{l}\text { Rostok-2P-K GOST R } 12.4 \text { 191-99 DSTU EN } \\
\text { 149:2003 FFP2 }\end{array}$ & 143 & 3.16 & 0.77 & 3.71 & 1.02 \\
\hline 19 & SUP AIR 23150 FFP1 EN 149:2001 CE 0086 & 87 & 1.75 & 0.33 & 2.34 & 0.66 \\
\hline 20 & Lepestok-200, 1990, SKhMZ & 112 & 2.34 & 0.63 & & \\
\hline
\end{tabular}

test with aerosol indication. The respirator valve opens only during exhalation, allowing free air release. The presence of an exhalation valve also prevents the fogging of glasses, which is important for medical personnel [3]. Characteristics of medical masks and respirators are summarized in Table 3.

Suen et al. [12] investigated the effect of RPE tightness on the efficiency of pathogen filtration, in particular, by N95 (class FFP2) respirators. Changes in the respirator fit depending on the type of motor activity (normal breathing, deep breathing, vertical and horizontal head motion, conversation, and body bending) were evaluated using the quantitative fit test (QNFT) method based on measuring aerosol levels inside the RPE mask and in the environment (Table 4). It was found that leakages inevitably arose in the course of respirator use, which decreased the efficiency of imperfectly sealed RPE by up to $66.5 \%$ [13]. By the end of the trial, the respirators did not provide the required protection level in one third of participants. It should be noted that, according to the guidelines of the US Center for Disease Control and Prevention, it is forbidden to touch the respirator during its exploitation.

In the European Union, an important characteristic of respirator efficiency is the nominal protection coefficient: the ratio between aerosol concentrations in the environment and the inner space of the mask. For instance, for a respirator with aerosol trapping efficiency of $94 \%$, the nominal protection coefficient is equal to 16.25. Another significant parameter of RPE efficiency is their ability to decrease aerosol concentration in the inhaled air to the levels below the maximum allowable concentration (MAC). Thus, the respirator efficiency depends on its nominal protection coefficient and on the ratio between the actual concentration of a contaminating agent and its MAC. For SARS-CoV-2, the MAC value is currently 
Table 3. Performance characteristics of medical masks and respirators [3]

\begin{tabular}{|c|c|c|c|c|c|c|c|}
\hline $\begin{array}{l}\text { Protec- } \\
\text { tion class }\end{array}$ & Fit test & $\begin{array}{c}\text { Protec- } \\
\text { tion from } \\
\text { droplets }\end{array}$ & $\begin{array}{l}\text { Protection } \\
\text { type }\end{array}$ & $\begin{array}{l}\text { Filtering } \\
\text { efficiency }\end{array}$ & $\begin{array}{l}\text { Internal } \\
\text { leakage }\end{array}$ & $\begin{array}{l}\text { Equivalent } \\
\text { class }\end{array}$ & Comments \\
\hline $\begin{array}{l}\text { Medical } \\
\text { mask }\end{array}$ & $\begin{array}{c}\text { Not } \\
\text { needed }\end{array}$ & Type IIR & Droplets & Varies & Varies & & $\begin{array}{l}\text { Free fit; No protection } \\
\text { during inhalation }\end{array}$ \\
\hline FFP1 & Needed & Type IIR & $\begin{array}{l}\text { Droplets } \\
\text { and particles }\end{array}$ & $>80 \%$ & $<22 \%$ & & $\begin{array}{l}\text { Available with a exhala- } \\
\text { tion valve }\end{array}$ \\
\hline FFP2 & Needed & Type IIR & $\begin{array}{l}\text { Droplets } \\
\text { and particles }\end{array}$ & $>94 \%$ & $<8 \%$ & $\begin{array}{c}\text { N95/ } \\
\text { P95/R95 }\end{array}$ & $\begin{array}{l}\text { Available with a exhala- } \\
\text { tion valve }\end{array}$ \\
\hline FFP3 & Needed & Type IIR & $\begin{array}{l}\text { Droplets } \\
\text { and particles }\end{array}$ & $>99 \%$ & $<2 \%$ & $\begin{array}{l}\text { N100/N99/ } \\
\text { P100/P99/ } \\
\text { R100/R99 }\end{array}$ & $\begin{array}{l}\text { Available with a exhala- } \\
\text { tion valve }\end{array}$ \\
\hline $\begin{array}{l}\text { Elastomeric } \\
\text { respirator }\end{array}$ & Needed & & $\begin{array}{l}\text { Droplets } \\
\text { and particles }\end{array}$ & $\begin{array}{l}\text { Exchangeable } \\
\text { filters }\end{array}$ & $\begin{array}{l}\text { Exchangeable } \\
\text { filters }\end{array}$ & & $\begin{array}{l}\text { Expensive reusable half- } \\
\text { mask }\end{array}$ \\
\hline PAPR & $\begin{array}{c}\text { Normally } \\
\text { not needed }\end{array}$ & & $\begin{array}{l}\text { Droplets } \\
\text { and particles }\end{array}$ & $\begin{array}{l}\text { Exchangeable } \\
\text { filters }\end{array}$ & $\begin{array}{l}\text { Exchangeable } \\
\text { filters }\end{array}$ & & $\begin{array}{l}\text { Reusable powered respi- } \\
\text { rator; expensive; pro- } \\
\text { longed operation time }\end{array}$ \\
\hline SAR & Needed & & $\begin{array}{l}\text { Source of } \\
\text { uncontami- } \\
\text { nated air for } \\
\text { breathing }\end{array}$ & $\begin{array}{l}\text { Source of } \\
\text { uncontami- } \\
\text { nated air for } \\
\text { breathing }\end{array}$ & $\begin{array}{l}\text { Source of } \\
\text { uncontami- } \\
\text { nated air for } \\
\text { breathing }\end{array}$ & & $\begin{array}{l}\text { Reusable respirator with } \\
\text { powered air supply; } \\
\text { expensive; can be con- } \\
\text { nected to an autono- } \\
\text { mous air source }\end{array}$ \\
\hline
\end{tabular}

Table 4. Results of the quantitative fit test [12]

\begin{tabular}{l|l|c}
\hline \multicolumn{1}{c|}{ Activity } & Baseline value & After activity \\
\hline Normal breathing & $197.80 \pm 10.81$ & $151.79 \pm 69.50$ \\
Deep breathing & $196.07 \pm 20.28$ & $150.47 \pm 68.73$ \\
Side-to-side head motion & $193.12 \pm 23.48$ & $150.34 \pm 70.24$ \\
Nodding & $188.38 \pm 29.19$ & $144.74 \pm 69.42$ \\
Conversation & $191.72 \pm 22.61$ & $152.29 \pm 61.30$ \\
Bending & $172.03 \pm 44.97$ & $129.10 \pm 72.68$ \\
Normal breathing & $184.86 \pm 33.74$ & $144.61 \pm 70.28$ \\
General coefficient of conformity & $184.02 \pm 26.73$ & $134.71 \pm 68.43$ \\
\hline
\end{tabular}

unknown; therefore, the protective characteristics of respirators cannot be assessed. However, a reasonable estimate of the nominal protection coefficient can be obtained based on the filtering performance of RPE.

For evaluation of respirator efficiency, filtration is considered as a function of aerosol penetration depending on the size of particles.

In a study by Konda et al. [14], the measured aerosol penetration through most fabric masks (cotton, silk, chiffon, flannel) varied within a broad range, from up to $85 \%$ for particles of $<0.3 \mu \mathrm{m}$ and up to $99 \%$ for particles of $>300 \mathrm{~nm}$ (Table 5). It was found that cotton (the most common material for cloth masks) performed better at higher weave densities. At the same time, a loose fit of the mask decreased filtration efficiency by more than $60 \%$ (Fig. 1). However, the cited data are highly questionable, since they disagree with the known general laws of aerosol trapping.

The effectiveness of wearing RPE was analyzed by air monitoring in a room with COVID-19 patients $[15,16]$. The size range of the detected aerosol particles was 20-1000 $\mathrm{nm}$. The patients were engaged in a minimal physical activity, such as conversation and nodding. The study analyzed two periods for which patients wearing masks stayed in the test room: $15 \mathrm{~min}$ and $3 \mathrm{~h}$. Aerosol concentrations were measured both in the room and inside the masks. It was shown that FFP2 respirators trapped pathogens more efficiently than conventional $3 \mathrm{M}$ medical masks. At the same time, $3 \mathrm{M}$ masks were 3 times more efficient than 
Table 5. Efficiency of filtration at the particle flow velocity of 1.2 CFM* [14] $^{*}$

\begin{tabular}{l|c|c|c}
\hline \multirow{2}{*}{\multicolumn{1}{c}{ Specimen/fabric }} & \multicolumn{2}{c}{ Filter efficiency, \% } & Pressure \\
\cline { 2 - 3 } & $<300 \mathrm{~nm}$ & $>300 \mathrm{~nm}$ & $\Delta P, \mathrm{~Pa}$ \\
\hline N95 (no gap) & $85 \pm 15$ & $99.9 \pm 0.1$ & 2.2 \\
N95 (with a gap) & $34 \pm 15$ & $12.0 \pm 3.0$ & 2.2 \\
Medical mask (no gap) & $76 \pm 22$ & $99.6 \pm 0.1$ & 2.5 \\
Medical mask (with a gap) & $50 \pm 7$ & $44.0 \pm 3.0$ & 2.5 \\
Single-layer cotton bandage (80 TPI**) & $9 \pm 13$ & $14.0 \pm 1.0$ & 2.2 \\
Double-layer cotton bandage (80 TPI) & $38 \pm 11$ & $49.0 \pm 3.0$ & 2.5 \\
Flannel & $57 \pm 8$ & $44.0 \pm 2.0$ & 2.2 \\
Single-layer chiffon & $67 \pm 16$ & $73.0 \pm 2.0$ & 2.7 \\
Double-layer chiffon & $83 \pm 9$ & $90.0 \pm 1.0$ & 3.0 \\
Single-layer silk & $54 \pm 8$ & $56.0 \pm 2.0$ & 2.5 \\
Double-layer silk & $65 \pm 10$ & $65.0 \pm 2.0$ & 3.7 \\
Cotton/silk (with gap) & $37 \pm 7$ & $32.0 \pm 3.0$ & 3.0 \\
\hline
\end{tabular}

${ }^{*}$ CFM, cubic foot per minute, unit of volume flow of gases and liquids $\left(1.2 \mathrm{CFM}=33980.2 \mathrm{~cm}^{3} / \mathrm{min}\right)$.

**TPI, threads per inch, unit of tissue density $\left(80 \mathrm{TPI}=12.4\right.$ threads per $\left.\mathrm{cm}^{3}\right)$.

hand-made three-layer cotton masks. The filtration efficiency of cotton and $3 \mathrm{M}$ masks tested using sodium chloride aerosols with a penetration velocity of $5.5 \mathrm{~cm} / \mathrm{s}$ was 86.4 and $99.9 \%$, respectively [15].

\section{PROPAGATION OF SARS-CoV-2 IN THE AIR}

Respiratory viral infections are primarily transmitted via two pathways: contact (direct or indirect) and aerosol (solid and liquid particles) [17]. Bioaerosols are airborne dispersed systems where the dispersed phase is composed of living organisms (bacteria or spores of plants and fungi) or their fragments, or includes biological agents capable of proliferating in living cells. Finely dispersed aerosols play a central role in transmission of respiratory infections, including SARS-CoV-2. In contrast to larger droplets and particles, finely dispersed particles can remain sus- (a)

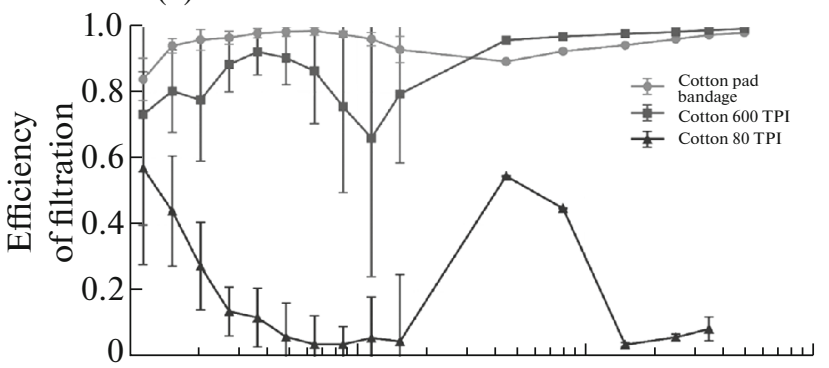

(c)

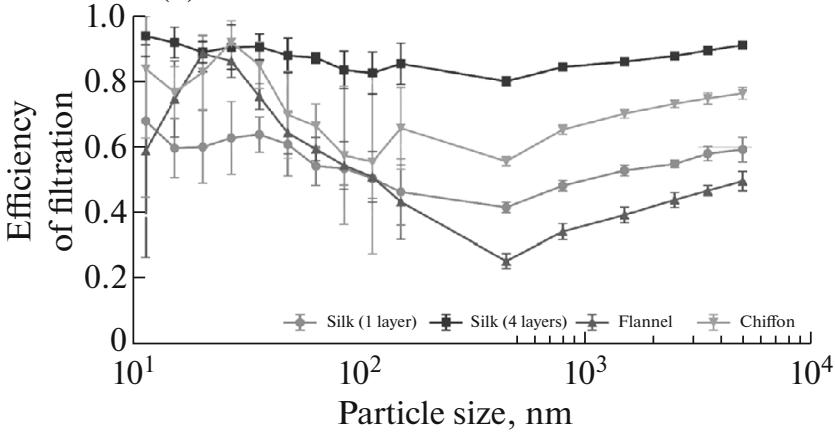

(b)

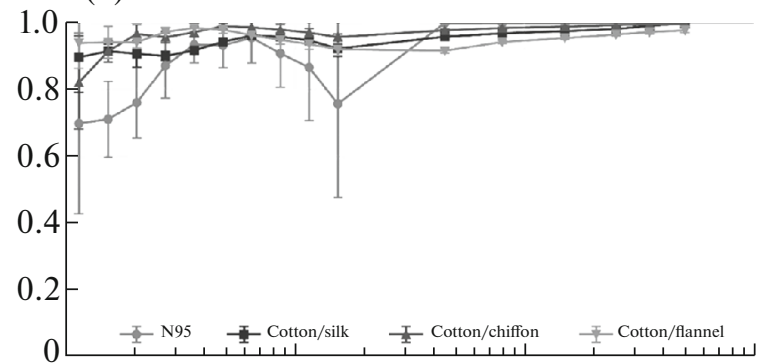

(d)

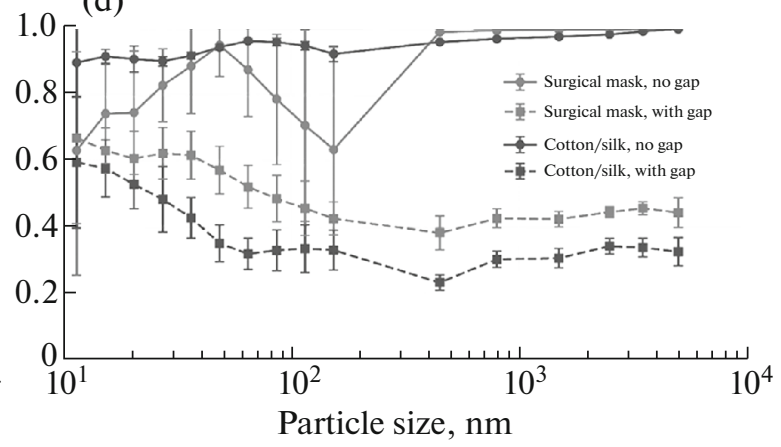

Fig. 1. Efficiency of filtration by various materials [14]. 


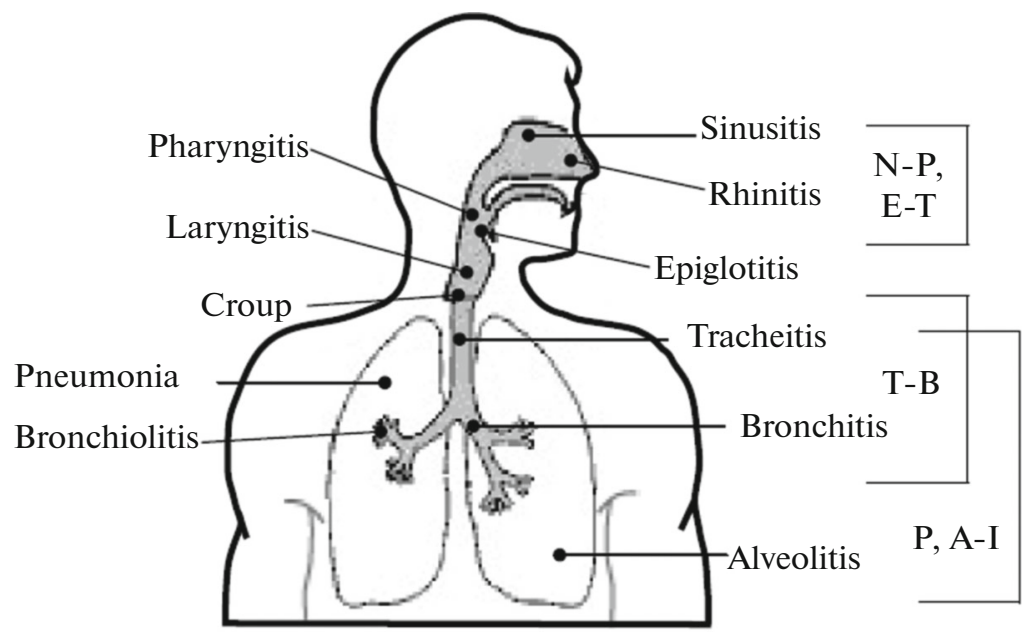

Fig. 2. Clinical manifestations associated with precipitation of aerosols containing infectious agents or allergens in different parts of the respiratory tract. N-P, nasopharyngeal; E-T, extrathoracal; T-B, tracheobronchial; P, pulmonary; A-I, alveolar-interstitial [18].

pended in the air for a long time because of their small size. In the respiratory tract, bioaerosols can cause infectious disease or toxicosis. The size of particles constituting the dispersed phase of bioaerosols of various origin ranges from dozens of nanometers to dozens of micrometers; as a result, their sedimentation can occur in all parts of the human respiratory tract (Fig. 2).

The sources of virus-containing particles are individuals with respiratory infections. When such a person breaths through their nose or mouth, talks, coughs, or sneezes, pathogen-containing particles of saliva and mucus are released into the air. The concentration of these particles can be as high as 25003000 per $\mathrm{cm}^{3}$ [19]. SARS-CoV and SARS-CoV-2

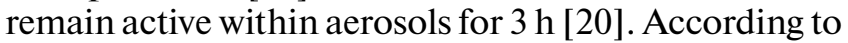
[21], the minimum infective dose of a pathogen transmitted by aerosols with a particle size of less than $5 \mu \mathrm{m}$ is by nearly two orders of magnitude lower than for transmission via large droplets produced by coughing and sneezing. This demonstrates the crucial role of aerosols in SARS-CoV-2 transmission and the need to utilize high-efficiency RPE.

For a susceptible individual, the risk of contracting a respiratory infection depends on a number of factors: on the concentration of the infectious agent determined by the abundance of pathogens in the exhaled air, on the size of bioaerosol particles, on their initial velocity, and on the distance from the point of aerosol production (taking into account sedimentation of large particles on surfaces, loss of pathogen viability in aerosol, convection and other flows that keep larger particles suspended). Furthermore, transmission of many respiratory infections is described by the Pareto principle, or the 20/80 rule: approximately $20 \%$ of infected individuals are responsible for $80 \%$ cases of transmission [22], since they release significantly higher quantities of pathogens than an average infected person.

To induce a disease, the virus load in an organism should exceed a certain threshold value, the minimal infective dose. The quantitative parameter generally used to describe this random value is $50 \%$ human infectious dose (HID50), i.e., the number of pathogenic agents that cause disease in $50 \%$ of individuals in the population. For instance, for seasonal influenza, the airborne HID50 ranges from 90 to 1950 copies of viral RNA [23], while for 2019-nCoV, tissue-culture ID50 was 500 to 3000 virus copies [24].

To obtain a rough estimate of the minimal size of an aerosol particle that contains 500 copies of viral RNA and surpasses HID50, let us consider viral capsids that form it as spheres packed in a hexagonal closed-packed lattice. Taking the total pathogen mass equal to the mass of an individual aerosol particle with a density of $\frac{\pi}{3 \sqrt{2}}$ (the maximum possible density of sphere packing), it is possible to calculate its equivalent radius, which constitutes $263-614 \mathrm{~nm}$ (Fig. 3).

The body of data concerning the sizes of bioaerosol particles released by forced expiration during coughing and sneezing published in various studies from 1899 to 2010 was summarized by Gralton et al. [25]. In spite of considerable divergence in the data on aerosol dispersion reported by different authors cited in [25], it is still possible to arrive to certain conclusions. First, the size of particles varies within a broad range: from submicron to dozens and hundreds of micrometers. Second, some individuals produce significantly more particles than other, which may facilitate transmission, especially during presymptomatic or asymptomatic infection. This conclusion is consistent with the Pareto principle. Third, typical counts of the exhaled particles ranged from $1000 \mathrm{~cm}^{-3}$ in children to up to 


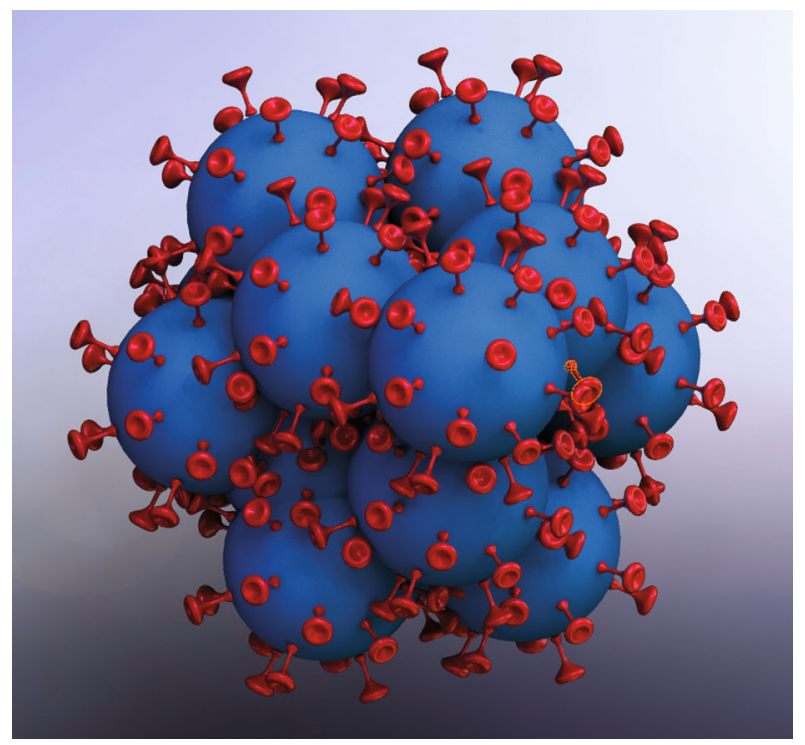

Fig. 3. (Color online) Aerosol particle containing 500 copies of viral RNA.

$4000 \mathrm{~cm}^{-3}$ in adult men while the velocity of air evacuation from the nasopharynx reached $8 \mathrm{~m} / \mathrm{s}$ [26].

To understand the causes underlying the great dispersion of particle sizes, let us consider the dynamics of aerosol behavior after their release from an organism. Respiratory particles are composed primarily of water, dissolved salts and glycoproteins, as well as pathogens. The released particles contain approximately $90 \mathrm{mM} \mathrm{Na}{ }^{+}$and $100 \mathrm{mM} \mathrm{Cl}^{-}$with mass concentration of 2.1 and $3.6 \mathrm{~g} / \mathrm{L}$, respectively, and $\sim 76 \mathrm{~g} / \mathrm{L}$ glycoprotein. As a consequence, even a completely dehydrated particle that does not contain pathogens has a nonzero terminal size [27].

After expiration, a particle with diameter $d_{0}$ is released into the ambient air, which has lower temperature and relative humidity $(R H)$ than the air in the respiratory tract. Its evaporation rate depends on the difference between the water vapor concentrations at the surface of the particle (saturated steam concentration) and in the ambient atmosphere. The presence of dissolved salts decreases the water steam pressure in the particle, increasing its equilibrium diameter. According to the estimates obtained in [27], at ambient $R H$ of 30 to $70 \%$, the equilibrium diameter of a droplet containing nonvolatile components in the concentration of $88 \mathrm{~g} / \mathrm{L}$ lies in the range from $0.47 d_{0}$ to $0.61 d_{0}$. At $R H=50 \%$, a $30-\mu \mathrm{m}$ droplet reaches the equilibrium diameter within $\sim 1 \mathrm{~s}$. A high expiration velocity accelerates this process.

Along with diminishing their size, evaporation of droplets changes their $\mathrm{pH}$ and temperature and increases the salt concentration. These changes have various effects on viruses and may cause their inactivation [28]; furthermore, an infectious agent may be

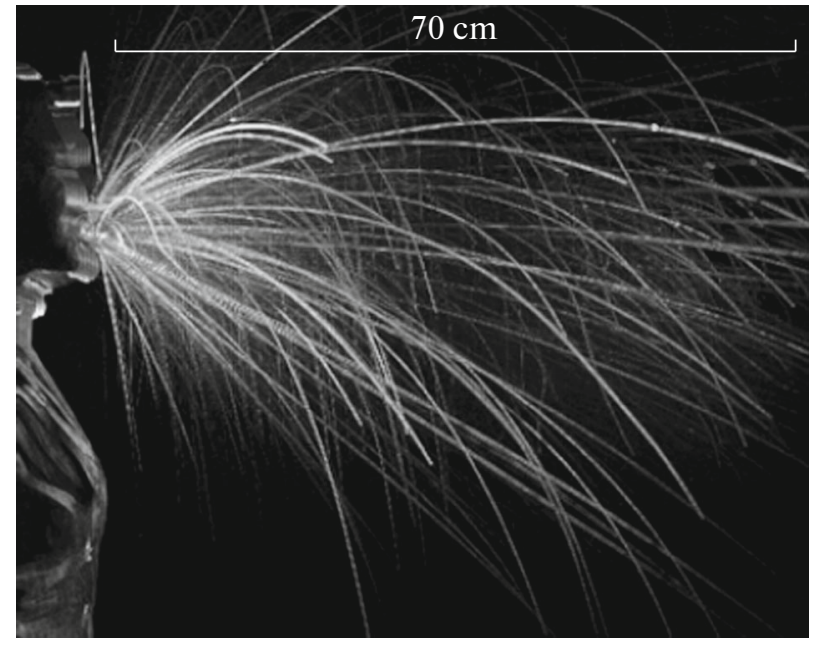

Fig. 4. Trajectories of particles released by coughing [32].

damaged by surface tension forces, shear stress, and conformational rearrangement of proteins as a result of dehydration. Nevertheless, it was shown that at least $63 \%$ of MERS-CoV particles remained infectious after $60 \mathrm{~min}$ at $25^{\circ} \mathrm{C}$ and $R H=75 \%$ [29], while for SARS-CoV-2 the survival period is at least $3 \mathrm{~h}$.

Among the forces acting on a sufficiently large particle $(>10 \mu \mathrm{m})$, the gravitational component prevails. For spherical particles in still air, the rate of sedimentation is described by the Stokes formula. For instance, for particles with a density of $1 \mathrm{~g} / \mathrm{cm}^{3}$ and aerodynamic diameters of 20,10 , and $5 \mu \mathrm{m}$, the time of sedimentation from the height of $3 \mathrm{~m}$ in still air constitutes 4, 17, and $67 \mathrm{~min}$, respectively. However, in the presence of heat convection and air flows from supplyand-exhaust ventilation, particles of less than $5 \mu \mathrm{m}$ in diameter can remain suspended over long period of time [30], and their concentrations decrease as a result of diffusion and coagulation processes.

Evolution of airborne bioaerosols was also simulated in [31]. It was found that the time of evaporation was proportional to $d^{2}$, while the terminal size of a droplet was proportional to its initial size and constituted $\sim 0.45 d_{0}$, which is consistent with the data from [27].

Let us briefly discuss the primary characteristics of a virus-containing airborne dispersed system and the mechanisms of its evolution in a closed space. A newly emitted turbulent multiphase cloud of particles is moving away from the source due to the initial impulse. Figure 4 shows the trajectories of particles released by coughing as recorded using high-speed photography (1000 images per second).

Measurements of primary droplets [33] showed that their size distribution was described either by a lognormal distribution with a mass median aerodynamic diameter $(M M A D)$ of $>300 \mu \mathrm{m}$ or by a bimodal distribution resulting from superposition of two log- 
normal distributions with $M M A D$ values of 72 and $386 \mu \mathrm{m}$. In both cases, the standard geometric deviation did not exceed 1.8.

While the particles are moving away from the source, their velocity relative to the medium rapidly drops to zero because of Stokes resistance (within the relaxation time $\tau$ equal to several fractions of second), whereas the aerosol cloud expands. Coarse particles leave the cloud due to gravitation. At the same time, the particles diminish as a result of evaporation (for instance, according to the Fuchs equation, at $20^{\circ} \mathrm{C}$ and $R H=50 \%$, a pure water droplet of $2 \mu \mathrm{m}$ in diameter has a lifetime of $0.24 \mathrm{~s}$ [34]).

Considering that droplet evaporation occurs rapidly, it is not surprising that the reported aerosol size distributions vary significantly among studies [3537]. The first possible reason is that the particle sizes were measured at different moments of time after their release in the air. Secondly, different techniques of sample collection and analysis were used; furthermore, these methods are basically inappropriate to obtain exact estimates of the size distribution parameters. Most of these works utilized Andersen cascade impactors (e.g., in [38-40]), a NIOSH two-stage cyclone sampler developed in the National Institute of Occupational Safety and Health [35], laser aerosol spectrometers [41, 42], polycarbonate filters [39], personal impactors with a teflon filter as the last cascade [43], as well as impingers, centrifuges, nucleopore filters [18, 44], and mobility analyzers [19].

According to different studies conducted using Andersen impactors, the fraction of particles with $M M A D<4.7 \mu \mathrm{m}$ constituted from 0.58 to 0.96 ; the counted median particle diameter determined using laser spectrometers was 0.63 [41] and $\sim 0.2 \mu \mathrm{m}$ [19]. The fraction of particles with $M M A D<1 \mu \mathrm{m}$ that passed through impactor cascades sometimes exceeded 0.90 .

It was also found that influenza viruses were mainly associated with particles of the submicron range [36]; moreover, normal breathing produced a significantly larger fraction of submicron particles than coughing (Fig. 5).

Apparently, it is impossible to determine the size of virus-containing particles more precisely, since inertial sedimentation currently does not allow separating submicron particles $(M M A D<1 \mu \mathrm{m})$ into several further fractions. On the other hand, a laser spectrometer cannot discriminate between virus-containing particles and the background aerosol; at the same time, the minimal detectable size is limited by the wavelength of the coherent radiation used. It should also be noted that filters collect nearly all particles present in the air, including those that do not make part of bioaerosols, and the collected particles continue evaporating from the filter.

Nevertheless, it seems highly likely that, in the air medium, a virus-carrying particle shrinks within frac-

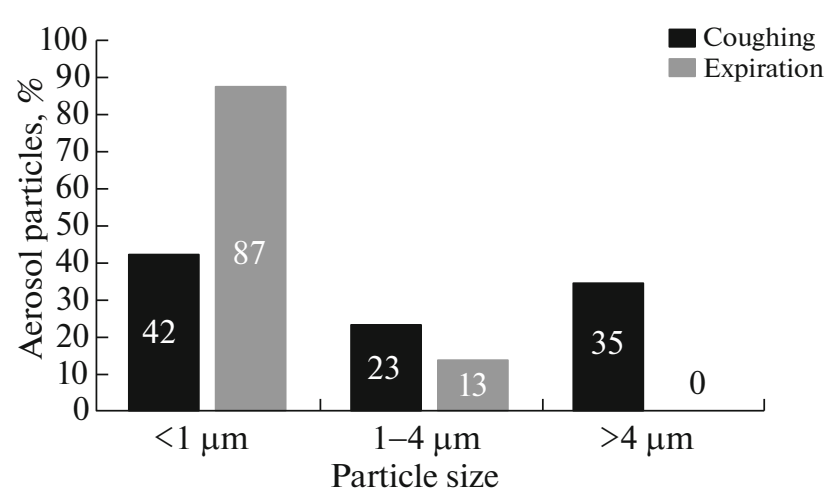

Fig. 5. Size distribution of aerosol particles carrying influenza viruses produced by coughing (black bars) and air expiration (gray bars) [36].

tions of a second to the size corresponding to its insoluble component, which also includes viruses. Apparently, the median diameter of the particles that remain suspended for a long time lies within the range of $0.2-$ $0.6 \mu \mathrm{m}$, considering that numerous studies indicate that aerosols with the highest atmospheric stability are composed of particles lying in this size range [45]. This notion is indirectly supported by the data from various studies $[41,19,46]$ that measured bioaerosols without separating them from the background aerosols and found that the sizes of these mixtures corresponded to the size of the most stable particles. Stability of these aerosols is due to low sedimentation rates and high diffusion coefficient of their particles; therefore, a decrease in the concentration of coagulating smaller particles and production of new larger particles as a result of coagulation is balanced by sedimentation of the latter.

It should be noted that the results of the size distribution measurements somewhat disagree with the calculations performed by Nicas et al. [27] and the data reported by Parienta et al. [31]. However, the estimates in [27] were very crude, and the study [31] actually investigated only the range of aerodynamic diameters of more than $0.7 \mu \mathrm{m}$. Particles of $\beta$-active aerosols produced by sedimentation of atomic decay products on condensation nuclei following radiation accidents and fires on territories contaminated with radionuclides (e.g. ${ }^{137} \mathrm{Cs},{ }^{131} \mathrm{I},{ }^{106} \mathrm{Ru}$, etc.) [47-49], of radioactive aerosols of natural origin containing isotopes of beryllium, sulfur, phosphorus, and radon daughter products $[50,51]$, as well as of inactive condensation aerosols [52], are detected in the same size range: $0.2-$ $0.7 \mu \mathrm{m}$. This means that particles carrying viruses, including coronaviruses, are of the most penetrating size for filtering materials used for aerosol trapping (Section 5). Considering that reliable RPE that decrease the concentration of particles 50-100 times have been developed to prevent contamination of human organism with radioactive aerosols, similar 


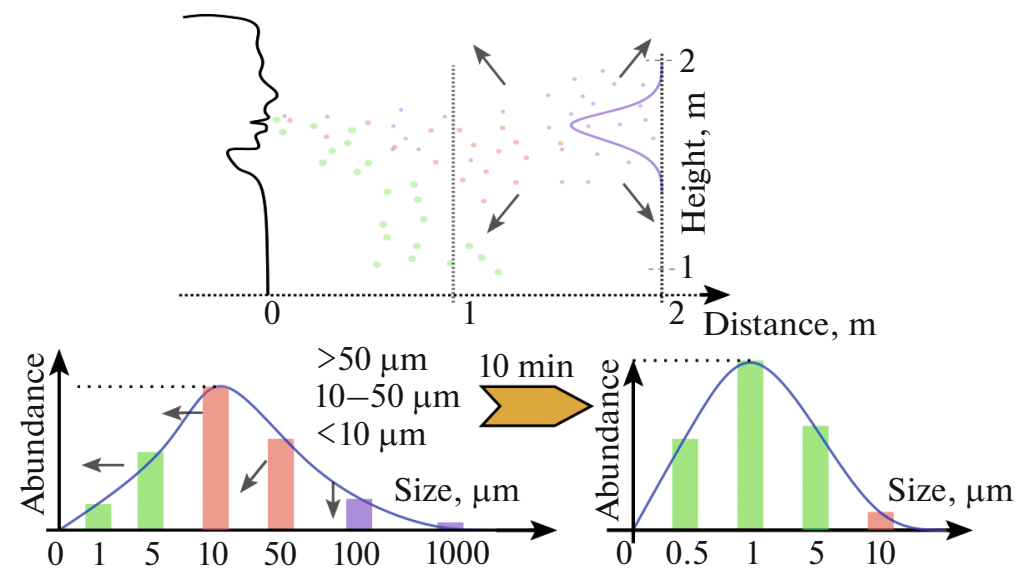

Fig. 6. (Color online) Spatial and temporal evolution of bioaerosols after forced expiration.

equipment can be used for protection from bioaerosols, including those that contain coronaviruses.

It can be assumed that particles released from the respiratory tract of an infected person not wearing a mask rapidly decrease in size. The largest ones $(>100 \mu \mathrm{m})$ sediment on the surfaces at a distance of $\sim 1 \mathrm{~m}$, whereas smaller particles reach the equilibrium size and within several seconds spread over a distance of $2 \mathrm{~m}$ with maximum concentration along the direction of the forced expiration; after 5-10 min, they can be detected over the entire volume of a closed room [53] (Fig. 6). Importantly, the strongest hazard is associated with submicron particles of $0.2-0.6 \mu \mathrm{m}$, which penetrate the alveolar regions of the lungs, while both smaller and larger particles sediment in the upper respiratory pathways due to diffusion and inertia, respectively.

The above substantiates the need for development of high-efficiency RPE against bioaerosols with a size range from dozens of nanometers to dozens of micrometers with low aerodynamic resistance and secure face line. Sufficient availability of such RPE is especially important during pandemics of respiratory viral infections.

\section{THEORETICAL BASIS OF BIOAEROSOL FILTRATION}

Protective properties of RPE are usually determined by the efficiency of the filtering materials used, which, in turn, depends on their structural characteristics. The choice of materials with specific parameters is based on the known principles of high-efficiency aerosol trapping by fibrous structures. The method of filter production plays almost no role, except for the case where filter efficiency is mainly determined by the electrostatic charge of the fibers. At the same time, the method of obtaining materials with required structure is of crucial significance if the parameters of the resulting structure can be controlled within a wide range of values by varying the mode of fiber production [54] or configuration of the equipment [55].

Let us briefly discuss the main principles of filtration by fibrous materials. First of all, it would be incorrect to compare aerosol filters to a sieve that captures particles greater than the mesh size, since this comparison does not explain the significantly higher efficiency of fibrous filters. The volume fraction of filter fibers rarely exceeds $8-10 \%$, while the filtration efficiency can be as high as $99.99 \%$ (HEPA filters). The sieve effect applies only to very large particles that can hardly be considered aerosols because of their high sedimentation rates (more than $1 \mathrm{~cm} / \mathrm{s}$ ).

The efficiency of filtration $(E)$ and the pressure drop on the filter $(\Delta P)$ are macroscopic parameters, and their values determine the principal consumer characteristics of the filtering material. The relationship between the filtration efficiency and the capture coefficient of an individual fiber $(\eta)$ is described by the following expression:

$$
E=1-K=1-e^{-\frac{4 \alpha H}{\pi d_{\mathrm{f}}} \eta}
$$

where $K$ is aerosol penetration $(K=1-E), \alpha$ is filter packing density, $H$ is filter thickness, and $d_{\mathrm{f}}$ is fiber diameter. In the theory of filtration, the capture coefficient (a microscopic parameter) is defined as the ratio between the number of particles $\left(N_{1}\right)$ that encountered a fiber of unit length and the number of particles $(N)$ contained in the flow of the width equal to the fiber diameter $\left(d_{\mathrm{f}}\right)$. Importantly, the value of $N$ is determined at a sufficient distance from the fiber, i.e., in the undisturbed flow: $\eta=\frac{N_{1}}{N}$.

The components of the capture coefficient $\eta=\sum_{k} \eta_{k}$, where $k$ is the summation index, are determined by various filtration mechanisms: diffusive deposition, interception, inertia, electric interaction, sedimentation, and van der Waals forces. The initial 
value of the capture coefficient is a function of a large number of parameters characterizing the filter (average fiber diameter and fiber size distribution, packing density, thickness and structure of fiber material, fiber surface, and fiber charge), aerosol particles (size distribution, particle density, and charge), and the gas flow (velocity, temperature, viscosity, pressure, and humidity). In case of nonstationary filtration, the capture coefficient can change with accumulation of the dispersed phase; as a consequence, the pressure drop and the filtration efficiency also change [56]. The difficulty in studying the process of aerosol filtration is related to the need to take into account the large number of parameters on which the exponent in formula (1) depends.

Considering the size range of virus-containing particles, filtration velocities (up to $10 \mathrm{~cm} / \mathrm{s}$ ), structural parameters of filters (fiber diameter, $0.3-2 \mu \mathrm{m}$; packing density, up to 0.1 ), and environmental parameters typical for RPE utilization indoors, the greatest contribution to respirator efficiency belongs to diffusion, interception, and electric interactions [57]. Although trapping of particles due to inertia is significant for analytical filtration, in this case it can be neglected, since the inertia parameter is below the threshold value [58].

The dependencies between aerosol penetration and filtration velocities were determined experimentally for industrial Petryanov filter fabrics from polymer fibers obtained by electrospinning [59]. They showed that, for filtration velocities of up to $10 \mathrm{~cm} / \mathrm{s}$, particle penetration increased with velocity for both charged and uncharged materials; furthermore, the difference between the penetration values at a given velocity was several orders of magnitude; $0.1-\mu \mathrm{m}$ particles exhibited lower penetration through FPP-15-1.5 than $0.34-\mu \mathrm{m}$ particles. At higher velocities (more than $10 \mathrm{~cm} / \mathrm{s}$ ), penetration first ceased to increase with growing velocity and then started decreasing.

These observations are readily explained based on the theory of filtration $[57,60]$ : with increasing particle size, the role of diffusion decreases and the role of interception increases; as a consequence, there exists the so-called most penetrating particle size (MPPS) for which the capturing efficiency is minimum. For a given material, the value of MPPS depends primarily on filtration velocity and decreases with its growth, while in the general case it depends on the same parameters that determine the efficiency (the capture coefficient). The theoretical MPPS value can be determined by taking the derivative of the analytical function of efficiency equal to zero.

To assess the possibility of using a given filtering material for particular purposes, it is important to evaluate not only its trapping efficiency, but also the pressure drop on the filter within the range of working velocities. It is especially important for fibrous materials utilized for RPE production. The number of mon- odispersed particles captured by a filter layer is proportional to the thickness of the layer and to the number of particles entering the filter. On the other hand, for low Reynolds numbers $(\mathrm{Re} \ll 1)$, the pressure drop is proportional to the linear velocity of the flow and to the layer thickness. Therefore, the dimensional parameter $\gamma=-\log K /(\Delta p / U)$, where $U$ is the filtration rate, can be used to describe the quality of filtering material and characterize the degree of aerosol removal per unit of pressure drop. Obviously, the higher the filter quality parameter, the better the filtering performance of the given material in comparison to other materials with the same pressure drop per unit of air flow velocity.

For instance, a most simple way of increasing the value of $\gamma$ is using materials made of charged fibers. As shown in Fig. 7, the penetration of $0.34-\mu \mathrm{m}$ particles (MPPS at flow velocity of $1 \mathrm{~cm} / \mathrm{s}$ ) differed between charged and uncharged FPP-15-1.5 fabrics by as much as four orders of magnitude. FPP-15-1.5 is the material most commonly used to manufacture Lepestoktype and similar respirators. However, the fiber charge decreases considerably in a humid atmosphere, which limits the duration of respirator use. It is possible to rely on predominance of the electric component of the capture coefficient if fibers are obtained from polymers with electret properties.

Another method of increasing the filtration efficiency while decreasing the pressure drop is decreasing the linear velocity of the flow through the filter. This can be achieved by increasing the area of the filtering surface and amounts to the possibility of modifying RPE design.

However, assuming that the respirator design should remain unchanged and the period of exploitation should be sufficiently long, it is necessary to consider other potential approaches to increasing filter quality.

A possible method of improving filter quality is creating a porous permeable layer on the fibers of the filtering material. This idea stems from the practice of nonstationary filtration, which shows that the efficiency of aerosol capturing rapidly increases with accumulation of sediment, whereas the hydrodynamic resistance of a dusted filter remains stable for a rather long time. The coefficients of diffusive capture of point particles and particles of finite size by equally spaced composite fibers of a model filter were calculated for low Reynolds numbers and a broad range of Péclet numbers (up to $10^{6}$ ) [61]. It was shown that by modulating the thickness of coating, the air flow rate, the layer porosity, and the packing density (distance between parallel fibers), the efficiency of filtration can be strongly increased, while the increase in flow resistance is low. It was found that filter quality increased at a lower packing densities of coating elements.

Porous fibers can be obtained using the electrospinning technique. Electron microscopy images in 

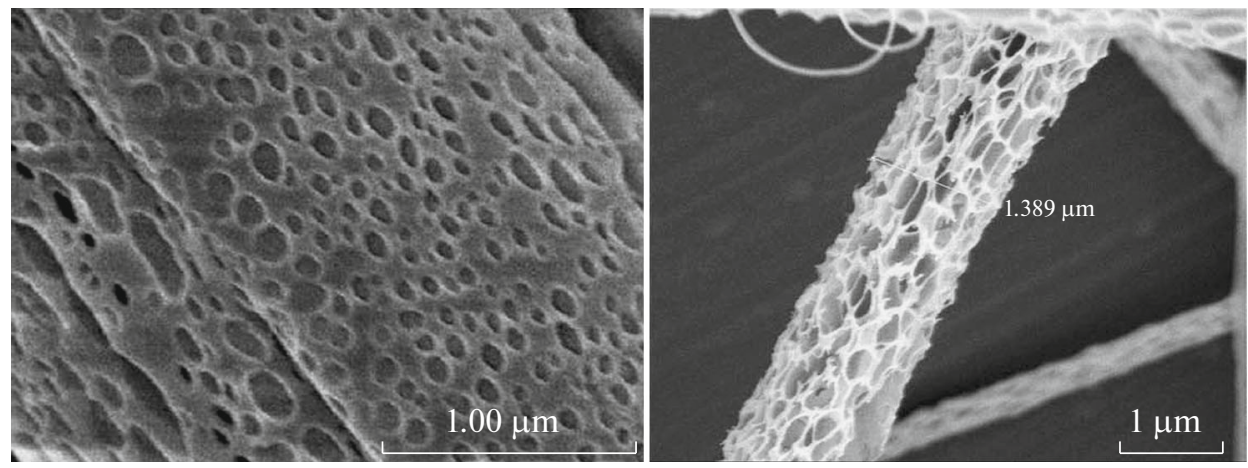

Fig. 7. Examples of porous fibers [63, 64].
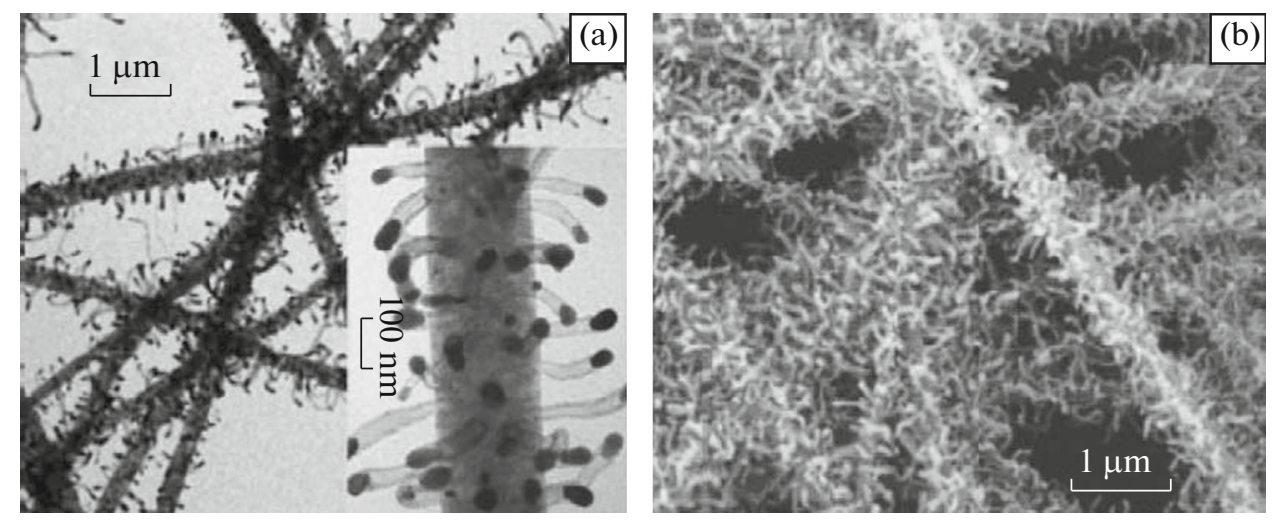

Fig. 8. Transmission (a) and scanning (b) electron microscopy images of carbon nanotubes on nanofibers obtained by electrospinning of polyacrylonitrile fibers, polyacrylonitrile carbonizaition, and catalytic growth of carbon nanotubes [65].

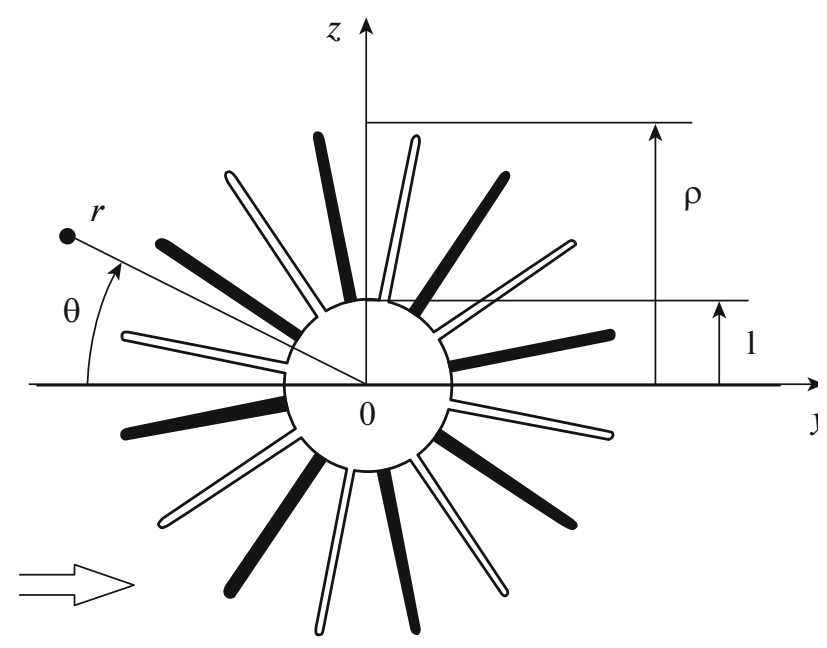

Fig. 9. Model cross-section of a composite fiber with nanofiber whiskers [66].

Fig. 7 show examples of this kind of fibers [62, 63]. It should be noted that these photographs only demonstrate the fundamental possibility of obtaining such fibers, but the optimal structure of both the fibers and the fibrous material should be determined by combining theoretical, experimental, and technological research based on the given conditions of filtration.

A promising approach to improving filter quality in the respiratory mode (at low filtration velocities) is development of filtering materials composed of fibers that are covered with whiskers of nanometer-range length (a specific case of porous fibers). According to [64], it is possible to obtain fibers that carry significantly thinner fibers of limited length positioned perpendicularly to the primary fiber surface. An example of technical implementation of this kind of structure is shown in Fig. 8 [65].

In [66], filter quality parameters were calculated for simulation filters composed of parallel cylinders with whisker coating. A cross-sectional model of the composite fiber used in the calculations is shown in Fig. 9.

It was found that the maximum effect of fiber coating was achieved for fibers with high Péclet numbers $(\mathrm{Pe})$. For $\mathrm{Pe}>10^{4}$, the capture coefficient for diffusive deposition of submicron particles of finite size increased several times. Similarly to the case of porous fibers, solving the optimization problem and determining the structural parameters of the fibrous filter 
are required to develop the method of filter production and to employ these structures in respirators.

Filtering materials composed of a mixture of micrometer and submicron range fibers are also considered promising for use in high-efficiency FPP3 respirators. An experimentally obtained mixture of 5- and $0.1-\mu \mathrm{m}$ fibers exhibited a resistance of $15 \mathrm{~Pa} \mathrm{~cm}^{-1} \mathrm{~s}^{-1}$ and efficiency of $99.9 \%$ by $100-\mathrm{nm}$ particles [67]. A micrograph of a similar structure obtained by Kim et al. [68] is shown in Fig. 10. To improve the filter quality in capturing particles of $0.2-$ $0.6 \mu \mathrm{m}$ at velocities under $10 \mathrm{~cm} / \mathrm{s}$, theoretical and experimental studies are required to determine the optimal proportions between fiber diameters and their fractions in the filtering material.

\section{METHODS USED FOR PRODUCTION OF FILTERING MATERIALS}

Most currently existing RPE utilize filters made of nonwoven fiber materials, which can be obtained using a number of techniques. One of the most popular methods is electrospinning: nonwoven materials of micrometer- and nanometer-sized fibers are obtained from polymer solutions or melts exposed to a strong electric field. Since the discovery of electrospinning in the Karpov Institute of Physical Chemistry in 1938, it has been extensively employed in the Soviet Union for production of filtering materials and various related items (e.g., RPE, industrial filters, or analytical filter bands). Important advantages of the electrospinning technique is the relative simplicity of the apparatus, the possibility of upscaling, flexibility, and high quality of the obtained fibers [69].

In the general form, electrospinning is a process of feeding a polymer solution through a metal spinneret connected to a high-voltage power supply. Next, the polymer jet moves within an electric field to the grounded deposition electrode (collector device), getting thinner and solidifying on the way, and forms there a fibrous layer ready for future use. Depending on the conditions of the process, the average diameter of the resulting fibers can vary within a broad range from dozens of nanometers to dozens of micrometers. Furthermore, various additives can be introduced into the polymer solution to provide the nonwoven materials with required functional properties: antibacterial, magnetic, or conductive [70].

The polymer solution can be fed by gravity, gas pressure, or a mechanical piston. The nozzle can be cylindrical or have the form of a spinning bowl, where the centrifugal force causes the solution to spread over the entire surface of the bowl and form numerous polymer jets between the electrodes. It was this technique that was employed for production of filtering materials in the Soviet Union [69]. Furthermore, electrospinning can be performed from a free surface using nozzle-free methods. For instance, this approach was

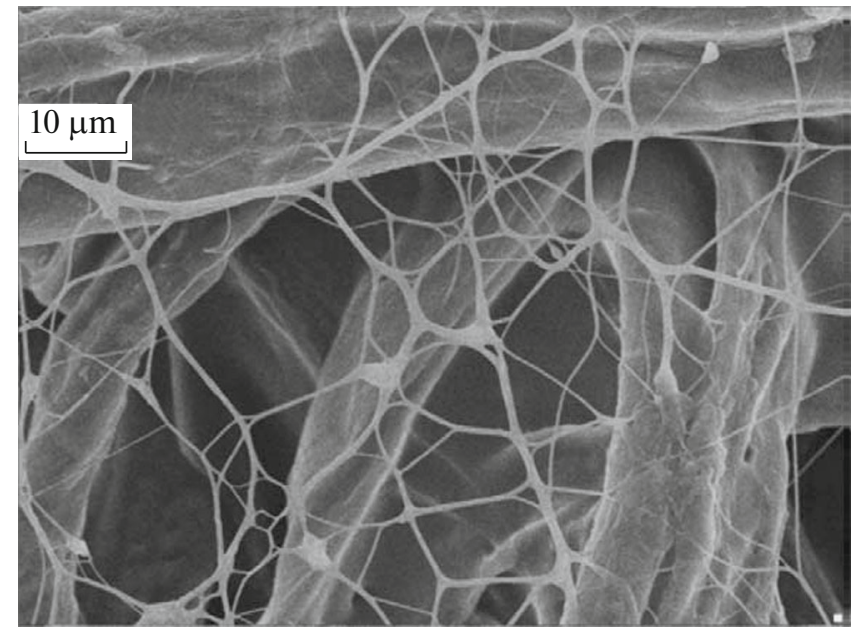

Fig. 10. Mixture of cellulose fibers obtained by electrospinning [12].

implemented by the Elmarco company for production of a material by Nanospider technology: a rotating metal electrode, to which a high-voltage potential was applied, was partially immersed into a container with a polymer solution. From the surface of the electrode, the solution was moved into the space between the electrodes where it formed the nonwoven material. According to the developers, the key advantage of this approach is that the number and mutual positioning of primary jets are set in a natural way, ensuring high productivity and maximum stability of the process, as well as uniformity of the resulting fibers [71]. Another nozzle-free technique is bubble electrospinning [13, 72]. According to this method, fibers are formed by numerous jets that issue from the hemispherical free surface of the bubbles produced by gas blowing through polymer solution to which the high voltage is applied. A similar technique patented by Stellenbosch Nanofiber Company under the name SNC BEST involves generating of a hemispherical free surface by spinning of a sphere immersed into a polymer solution [73].

Equipment for production of nonwoven materials from polymer solutions by electrospinning is currently proposed by a number of companies, such as MECC (Japan), Elmarco and SPUR (Czech Republic), Inovenso (Turkey), Ucalery (China), FNM (Iran), and other.

By means of electrospinning, it possible to obtain diverse nonwoven filtering materials of polymer fibers using the same equipment and changing only the fiber-forming nozzles (spinnerets) and the composition of the polymer solution. The nozzle-based variant of the process can be used for industrial production of materials with fiber diameter of 0.1 to $10.0 \mu \mathrm{m}$, fiber packing density of $2-10 \%$, and standard hydrodynamic resistance of the fiber layer $\left(0.2-10 \mathrm{~mm} \mathrm{H}_{2} \mathrm{O}\right)$ [54]. Combined materials composed of fibers with dif- 
ferent diameters can be formed by volume structuring or layer-by-layer mixing. The ratio between the length of different fibers may reach 20 : 1 (e.g., in FPP-3/203.0 composed of fibers with a radius of 0.18 and $0.75 \mu \mathrm{m})$ [55]. In FPP-Sh, which is composed of fibers with a radius of $0.21-0.23$ and $1.7 \mu \mathrm{m}$, the ratio between fiber lengths is $10: 1$ [55]. In the production of such filtering materials, it is possible to choose in advance their desired parameters and achieve them by modulating the number and resistance of fiber-forming elements, as well as the principal technological parameters: characteristics of the molding solution, throughput, distance between electrodes, voltage, and velocity of the collector electrode.

Using the electrospinning technique, filtering material can be manufactured both in the form of individual sheets of $1 \mathrm{~m}^{2}[54,55]$ and rolls [55].

In spite of its numerous obvious advantages, the method of solution electrospinning also has certain shortcomings related to using a solvent. First, many commodity polymers (first of all, polyolefins) have limited solubility, which makes their treatment in solutions basically unfeasible on the industrial scale. Second, organic solvents evaporate in the course of the process and need to be captured and regenerated. This problem can be solved by utilizing polymer melts.

Electrospinning of a polymer melt was first reported in 1981 [74]; however, due to extremely high viscosity of the melt, the resulting fibers had up to $400 \mu \mathrm{m}$ in diameter, which ruled out the possibility of their practical use. Subsequent optimization of the process parameters made it possible to obtain fibers of $\sim 1 \mu \mathrm{m}$ in diameter that can be employed in various fields, including production of filtering materials [75].

The processes of melt and solution electrospinning are generally similar, and their main difference concerns the implementation of the feeder: for melt electrospinning, the nozzles and the polymer-containing vessel require heating. The simplest way is to utilize a heated reservoir with a piston; however, such systems are suitable only for laboratory use. Another possibility is using extruders with several heating zones: the process can be up- and down-scaled according to current needs by flexible regulation of the number of nozzles and the melt feeding rate, and degradation of the polymer is diminished due to optimization of temperature conditions in different zones along the screw. Melt electrospinning can be used to obtain fibers not only through nozzles, but also from a free surface, e.g., using the bubble technique [76]. In addition, nozzlefree devices with laser-induced polymer melting have also been developed [77, 78]; however, it is extremely difficult to upscale this process from laboratory equipment even to the semi-industrial level.

For such purposes, an apparatus featuring a cluster of 64 nozzles was designed in the Aachen University (Germany) [79]. Another variant of transition from laboratory research to large-scale production of fibrous materials by melt electrospinning is the installation constructed in Beijing University of Chemical Technology [80]: the polymer is molten in a specially designed double-screw extruder and fed through an umbrella-type nozzle with a throughput of $100 \mathrm{~g} / \mathrm{h}$. Subsequently, the same research group constructed a pilot installation with parameters that allow full-scale industrial implementation: 32 umbrella nozzles, 50100 primary jets per nozzle, capacity of $300-600 \mathrm{~g} / \mathrm{h}$ with a possibility of modular expansion to $6 \mathrm{~kg} / \mathrm{h}$; the produced nonwoven sheet is $0.8 \mathrm{~m}$ wide with a layer thickness of $0.01-1 \mathrm{~mm}$ [81].

Another technology that is currently most widely employed for production of nonwoven fabrics is the melt blowing process. It includes the following stages: melting the polymer in an extruder, pressing the melt through nozzles with a large number of orifices, pickup of the liquid jet with a stream of hot air (150$300^{\circ} \mathrm{C}$ ) under a high pressure, which mediates its drawing into a fiber, collecting the material on a conveyor belt, and spooling. The typical fiber diameter obtained by the industrial melt blowing process is $1-$ $5 \mu \mathrm{m}$ (although there have been reports on obtaining submicron fibers). The most common input materials for meltblown nonwoven fabrics are polyolefins, primarily polypropylene (usually with low and ultralow molecular weight and a melt flow parameter of 500$2000 \mathrm{~g} / 10 \mathrm{~min}$ ); it is also possible to utilize other thermoplastic polymers, e.g., polystyrene or polybutylene terephthalate [82]. The pioneering company in the development and commercial implementation of this method was Exxon (currently, ExxonMobil), which holds a number of key patents related to the melt blowing process. The licenses were soon purchased by a number of large industrial companies, such as $3 \mathrm{M}$, Kimberly-Clark, and Johnson \& Johnson, which further obtained their own patents in this field [83]. Thus, melt blowing has become the principal technology used for industrial production of diverse filtering and absorbing materials worldwide. In Russia, meltblown fabrics have also been gradually replacing their domestic counterparts produced by electrospinning since the 1990s. As a consequence, many respirators currently manufactured in Russia feature a filtering layer made of fabrics obtained using the melt blowing process (e.g., Spiro respirators by the Kimry Gorky Factory) [8]).

Another method widely employed for industrial production of fibrous materials is the spunbond technique, which has been developing in Europe and the United States since the 1960s. Spunbond fabrics are obtained by melting a polymer (usually polypropylene, but other thermoplastics are also possible) in an extruder and pressing it through nozzles (the number of orifices can range from several dozens to several thousands, and their diameter is usually $0.25-$ $1.2 \mu \mathrm{m})$. Next, the fibers are drawn and cooled, deposited on a conveyor belt, bound, and spooled. The typical fiber diameter in these materials lies in the 
range of $20-40 \mu \mathrm{m}$. Drawing is performed either mechanically or aerodynamically; fiber bonding can be conducted using a number of methods, but the most common ones are calender thermobonding (for densities of up to $100-200 \mathrm{~g} / \mathrm{m}^{2}$ ) and needle-punching (for more dense materials). The drawing, cooling, and fiber deposition stages, which largely determine the parameters and quality of the resulting material, can be executed with various technological approaches; however, four variants have found most use in industrial production [84]. In the Docan system developed by Lurgi Kohle \& Mineraloltechnik in 1970, the fibers are first cooled and solidified in a column; then they are drawn by high-velocity air stream in a special chamber, and finally delivered on the conveyor belt. The second variant, the Reicofil technology, was first presented by Reifenhaeuser in 1976; it is distinguished by the fact that the entire process of fiber cooling, drawing, and deposition takes place in a closed column isolated from the ambient air. Next, the Lutravil system proposed by the Carl Freudenberg company in 1965 utilizes three-stage fiber cooling, whereas the third stage also involves fiber drawing by air supplied under high pressure. Finally, the AST technology was developed by the Ason company in the 1990s for highcapacity production of fine fibers; it is distinguished by using air streams not only for cooling and stretching, but also for fiber deposition, as well as by a shorter drawing zone.

Thanks to the combination of their features, such as high air permeability, hydrophobicity, chemostability, resistance to abrasion and crumpling, and lack of toxicity, as well as to low cost, spunbond materials are widely employed in the production of disposable clothing and personal protective equipment (as a rule, fabrics with a density of $40-60 \mathrm{~g} / \mathrm{m}^{2}$ are used), as agro- and geotextile, as well as sewing material (canvases with a density of up to $600 \mathrm{~g} / \mathrm{m}^{2}$ ). In masks and respirators, spunbond materials serve as preliminary filter capturing large particles and protect the principal filtering layer from mechanical damage.

Furthermore, combined multilayer materials of the SMS-type (spunbond-meltblown-spunbond) are currently widely manufactured and employed primarily in protective equipment [84].

In addition to the methods described above, which all have in various forms found an industrial implementation, two further techniques of nonwoven fabric production have been proposed during the recent decade and are currently under active development: solution blow spinning and centrifugal spinning.

In the solution blow spinning technique, the process driven by compressed air. It is attractive due to simplicity of the equipment: in contrast to the melt blowing process, there no need to heat the polymer and the compressed air, and in contrast to electrospinning, there is no need to apply high voltage. Furthermore, the method does not require a conductive receiver device and therefore can be used to apply fibers directly on biological substrates. The average diameter of the resulting fibers lies in the range from hundreds of nanometers to several micrometers, and large fabric sheets can be obtained by using multinozzle units [85]. This technique has the same limitations as solution electrospinning: it is necessary to capture and regenerate the evaporating solvent and it is impossible to obtain fibers from commodity polymers with limited solubility.

Centrifugal spinning (also called force spinning) can be used to obtain fiber structures from polymer solutions and melts $[86,87]$. In this process, the polymer is placed in a vessel connected to the motor shaft. As the motor starts rotating the vessel around its axis, the polymer solution (or melt) begins to squeeze out through narrow orifices in its walls under the influence of centrifugal forces, forming fibers on the receiving device. The simplest example of using this principle is the cotton candy machine. Similarly to solution blow spinning, centrifugal spinning produces fibers with an average diameter lying in the range from $200-300 \mathrm{~nm}$ to $5-10 \mu \mathrm{m}$. Furthermore, to improve the parameters of the resulting fibers, centrifugal spinning can be used in combination with electrospinning [88]; this approach was implemented by several plants in the Soviet Union.

In conventional nonwoven materials, fibers are randomly arranged relative to each other, even if they have generally the same orientation. However, there exists a possibility to obtain three-dimensional frames of an arbitrary shape and exactly controlled positioning of individual fibers. This is achieved by means of additive manufacturing, where fibers are applied in layers through the precise movement of either the forming head or the pickup device. This approach can be applied to different methods of fiber production, e.g., to stretching or local-field electrospinning. A broad range of polymers can be utilized for 3D-printing: polyamides, polypropylenes, acrylates, and polylactides [89].

Thus, there currently exist numerous techniques of obtaining nonwoven fiber materials designed for aerosol filtration, and three of them: electrospinning, melt blowing, and spunbond, are employed in industrialscale production.

\section{CURRENT DEVELOPMENTS IN RPE PRODUCTION}

In the current context of COVID-19 pandemics, there have been many publications aimed at increasing the filtration efficiency of respirators and presenting ideas on development of new RPE types. These works also propose diverse modifications of classical N95 respirators and their analogs, such as inserting linings from various types of sorbent materials, including 


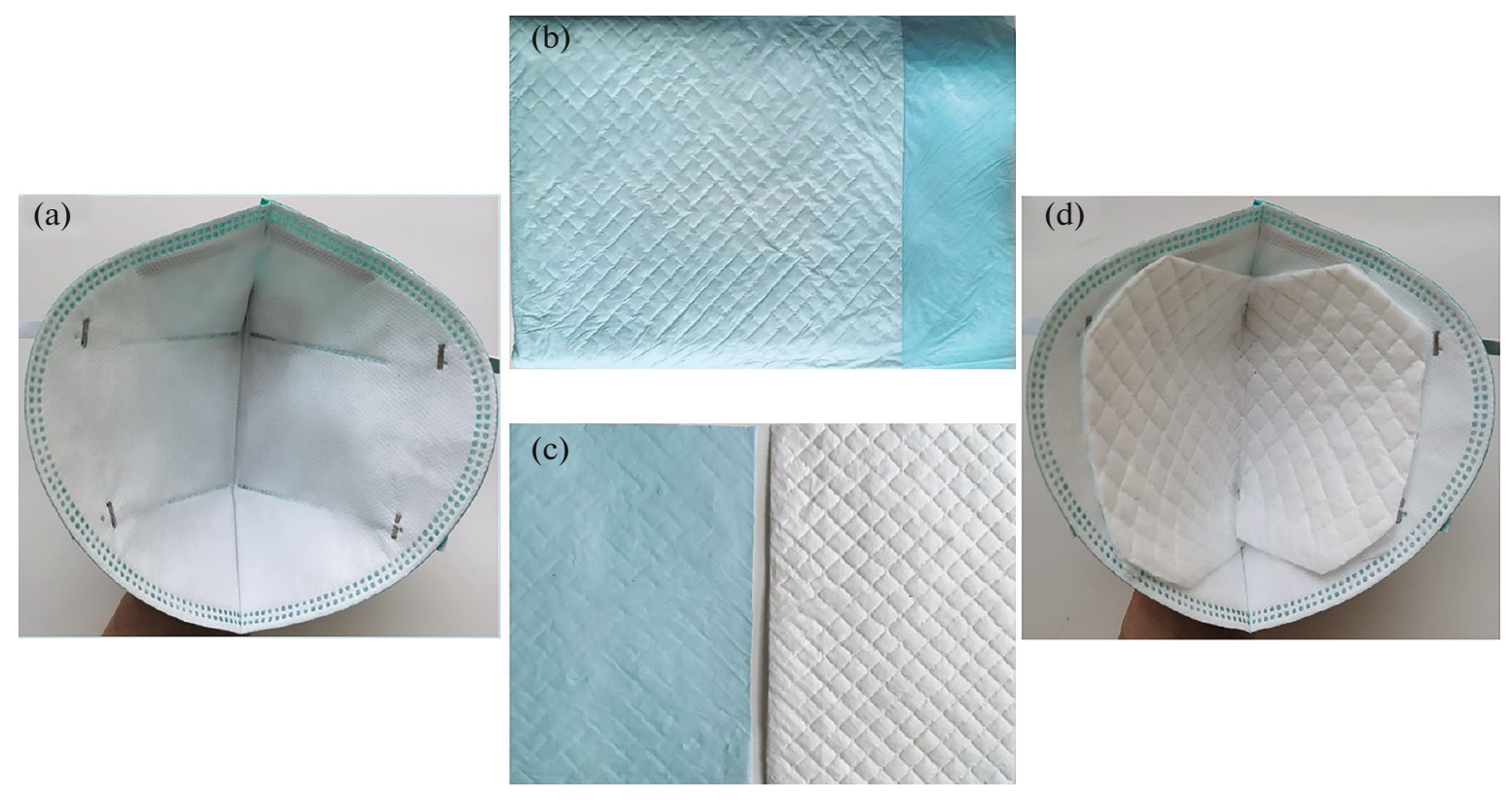

Fig. 11. (Color online) Modified N95 respirator with a liner of absorbent material: (a) N95 respirator; (b) superabsorbent pad; (c) separated layers of a superabsorbent pad: left, waterproof film, right, layer of superabsorbent polymer material; (d) N95 respirator with a liner of superabsorbent material [89].

those containing antibacterial components [90] (Fig. 11).

It was proposed to implement additive technologies to manufacture individualized RPE using 3D modeling and 3D printing [1]. After a user makes face scans with a smartphone, an individual polyamide mask frame for disposable filters can be printed. Commercially available disposable melt-blown filter membranes for FFP2/3 respirators can be used as filtering elements. However, the proposed design has a serious shortcoming: the mask frame is manufactured from rigid plastic, which results in poor sealing and, as a consequence, in leakage of contaminated air along the fitting line (Fig. 12).

Leung et al. [91] presented data on polyvinylidene fluoride-based filtering materials that can efficiently capture 100-nm particles, including nanometer-sized viral aerosols. Four fiber layers of 90, 200, 350, and $550 \mathrm{~nm}$ are provided to increase the dust capacity, and additional plasma treatment serves to enhance electrostatic filtration. The described filter design enables broad-band filtration in the range of 50-500 $\mathrm{nm}$, and plasma treatment enhances the efficiency of filtration of negatively charged virus particles.

In several studies, electrospinning was used to obtain filters from ordered polymer fibers [92, 93]. The authors argue that they exhibit improved resistance and filtering performance. At air flow rates of $\sim 16 \mathrm{~cm} / \mathrm{s}$, oriented fiber materials demonstrated high filter quality and 22 to $50 \%$ higher efficiency in comparison to unordered filters, depending on the size of the particles. Noteworthy, oriented nonwoven materi- als can be used to create conductive layers in electrostatic filters, which are characterized by high filtration efficiency [94]. By combining the possibilities of finetuning the morphology of the obtained nonwoven materials with utilization of external power supply, it may be possible to create active personal protective equipment.

Huang et al. [95] tested polysulfone membrane filters using dioctyl phthalate (DOP) and potassium chloride aerosols with particle sizes of $0.03-0.5 \mu \mathrm{m}$. It was found that solid particles exhibited higher penetration than liquid ones, presumably due to elastic scattering on membrane fibers. The MPPS value was $50 \mathrm{~nm}$ for liquid particles and $200 \mathrm{~nm}$ for solid particles. In the context of our review, aerosol particles can be considered both as liquid (exhaled by a COVID-19 patient) and as solid (after drying of liquid exhaled fractions or their sedimentation on solid particles of background aerosols). However, at low Reynolds numbers (velocity of inhalation through the filtering material), the efficiency of filtration does not depend on the phase state of aerosol particles.

It was proposed to use high-porosity antiseptic filler for respirators based on calcium phosphate and silver nanoparticles [87]. The filler has the form of powder with $50 \times 100 \mathrm{~nm}$ particles and contains up to $5 \mathrm{wt} \%$ silver nanoparticles. Calcium phosphate powder is formed as a 3-mm-thick replaceable RPE cartridge. According to Raghavan et al., the proposed filler should serve for antibacterial properties of the respirator and inhibit various viruses in the air flow. 

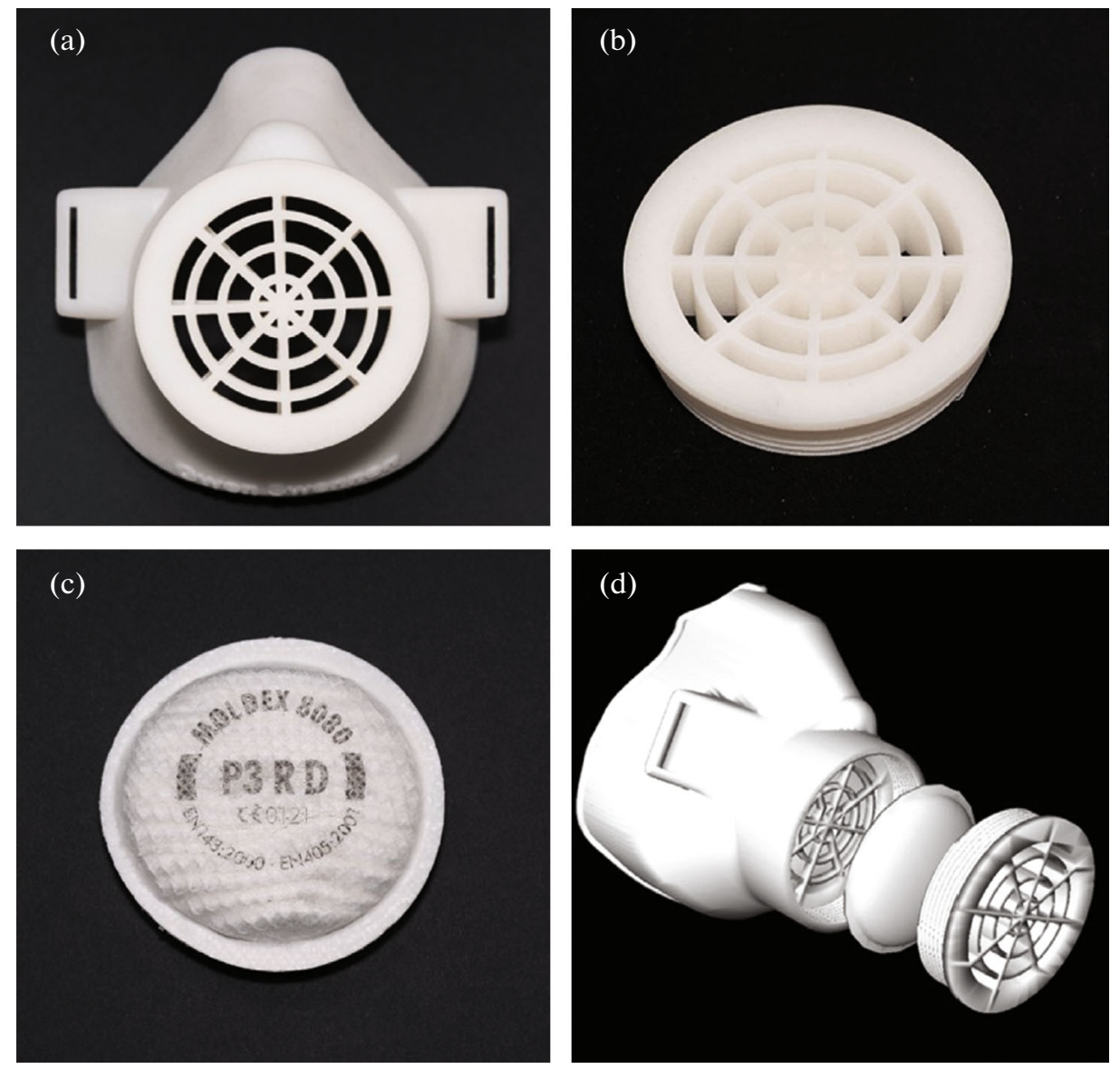

Fig. 12. (Color online) Individualized RPE obtained by 3D printing: (a) reusable half-mask, (b) support for a filtering membrane, (c) filter from polypropylene-based nonwoven material, and (d) 3D image of the prototype [1].

To sum up, various approaches have been proposed to enhance the efficiency of filtration and provide the materials of masks and respirators with antibacterial and antiviral properties. However, the major problems of air-tightness of mass-market RPE pieces and improving their sealing and, as a consequence, their consumer performance remain unsolved.

\section{CONCLUSIONS}

The review described the features of SARS-CoV-2: the virion shape and size, the median number of viral particles that cause infection in the human respiratory tract, and the level of virulence; they are compared to the characteristics of other common respiratory viruses.

The mechanisms underlying the formation of aerosols with liquid virus-containing dispersed phase during coughing, sneezing, and talking are discussed; the evolution of these airborne disperse systems due to evaporation, sedimentation, and coagulation is described. The estimated size range of terminal viruscarrying aerosol particles coincides with the size of the most stable radioactive aerosols that form the global atmospheric background $(0.2-0.5 \mu \mathrm{m})$. For this reason, protection from virus-containing aerosols can be achieved using the respiratory protective equipment designed and manufactured for protection from radioactive aerosols.

The currently available RPE types produced in different countries worldwide and used for protection from radioactive aerosols are described. It was shown that FPP2 and FPP3 respirators, when worn properly, protect the user's respiratory system from bioaerosols of various genesis. Respirators and masks that owe their protective properties mainly to the Coulomb interaction of particles and charged fibers are effective only for a short time and exhibit a significant decrease or loss of the fiber charge under unfavorable environmental conditions (e.g., at a high relative humidity or in the presence of elevated concentrations of airborne ions).

Requirements to respirators are specified. A shortcoming of high-efficiency respirators is that breathing generates a relatively high pressure drop on the filtering material (20-40 $\left.\mathrm{Pa} \mathrm{cm}^{-1} \mathrm{~s}^{-1}\right)$. Due to self-similarity of the flow through a fibrous structure at low Reynolds numbers, the pressure drop is proportional to the 
linear velocity of the air flow. During long-term utilization, as well as during physical activity, high-efficiency RPE cause discomfort to the users. Thus, decreasing the aerodynamic resistance to respiration while maintaining the filtration efficiency of respirators is a topical technical problem that should be solved to create RPE with improved consumer performance.

The mechanisms of aerosol capturing by fibrous filters are discussed. The macroscopic characteristics of a filter are its efficiency $E$ and the pressure drop $\Delta P$, while the filter quality parameter $\gamma=-\frac{\ln (1-E)}{\Delta P}$ describes the level of filtration per unit resistance. Obviously, more advantageous are filters with higher $\gamma$ values. In turn, the efficiency of the material is unambiguously determined by the coefficient of aerosol capture by a fiber of unit length, which depends on the properties of the flow field next to the fiber and on the characteristics of the particles (equivalent diameter, density, and charge), the filter (fiber diameter and packing density), and the gaseous medium (temperature, pressure, humidity, viscosity, and linear flow velocity), whereas the pressure drop depends on the structural characteristics of the filter and the properties of the medium.

It is shown that filter quality $\gamma$ can be improved by decreasing the $\Delta P$ value due to optimization of the structure of the fibrous filtering material. Structural modifications may involve using various mixtures of fibers of the micro- and nanometer range, producing fibers with a porous outer layer, or creating fibers that carry nanofibers of limited length positioned perpendicularly to the surface of the maternal fiber.

The methods of fibrous filter production from polymer solutions and melts (e.g., electrospinning) are described. They allow broad-range modulation of the structural parameters of the materials obtained: fiber diameter and microstructure, the manner of fiber arrangement (e.g., random Poissonian process, a specified angular distribution, or parallel fibers), and packing density. It is fundamentally possible to achieve the fiber characteristics that ensure the maximum filter quality.

In summary, this review substantiates the need for theoretical and experimental studies that would include the search for optimal structure of RPE materials, development of technological regulations for their production, manufacturing experimental samples of filtering materials, investigation of their hydrodynamic and filtering characteristics, production of prototype respirators, and testing their protective and consumer performance.

\section{FUNDING}

This study was supported by the Russian Foundation for Basic Research (project no. 18-29-17066mk) and the
National Research Center Kurchatov Institute as a part of the research topic plan.

\section{CONFLICT OF INTEREST}

The authors declare no conflict of interest.

\section{REFERENCES}

1. G. R. J. Swennen, L. Pottel, and P. E. Haers, Int. J. Oral Maxillof. 49, 673 (2020).

2. COVID-19 Dashboard, Center for Systems Science and Engineering, Johns Hopkins University. https://www.arcgis.com/apps/opsdashboard/index.html\#/bda7594740fd40299423467b48e9ecf6.

3. M. Ippolito, F. Vital, G. Accurso, et al., Pulmonology 26, 204 (2020).

4. W. W. F. Leung and Q. Sun, Sep. Purif. Technol. 245, 116887 (2020).

5. N95 Respirators, Surgical Masks, and Face Masks, US Food and Drug Administration.

https://www.fda.gov/medical-devices/personal-protective-equipment-infection-control/n95-resp iratorssurgical-masks-and-face-masks.

6. I. Boskoski, C. Gallo, M. D. Wallace, and G. Costamagna, Gastrointest. Endosc. 9, 519 (2020).

7. C. R. MacIntyre and A. A. Chughtai, Int. J. Nursing Studies 108, 103629 (2020).

8. Personal Respiratory Protection. Filtering Half Masks-Respirators, Kimry Gorky Factory. http://fgsiz.ru/product/category/index/path/73/.

9. Respirators of ALINA Series, Respiratory Complex. https://rkszpe.ru/respirator/.

10. Instructions and Documentation, Respiratory Complex. https://sizmed.ru/instruction/.

11. P. I. Basmanov and A. D. Shepelev, in Proceedings of the 8th Petryanov Readings, Moscow, June 28, 2011, p. 348.

12. L. K. P. Suen, Lin Yang, S. K. Suki, et al., Am. J. Infect. Control. 45, 974 (2017).

13. R. Yang, J. He, L. Xu, and J. Yu, Polymer 50, 5846 (2009).

14. A. Konda, A. Prakash, G. A. Moss, et al., ACS Nano 14, 6339 (2020). https://dx.doi.org/10.1021/acsnano.0c03252

15. K.-F. Ho, L.-Y. Lin, S.-P. Weng, and K.-J. Chuang, Sci. Total Environ., 33027 (2020).

16. E. E. Sickbert-Bennett, J. M. Samet, P. W. Clapp, et al., JAMA Intern. Med., 4221 (2020).

17. J. S. Kutter, M. I. Spronken, P. L. Fraaij, et al., Curr. Opin. Virol. 28, 142 (2018).

18. M. S. A. Heikkinen, M. K. Hjelmroos-Koski, M. M. Haggblom, and J. M. Macher, "Bioaerosols," in Aerosols Handbook: Measurements, Dosimetry and Health Effects, Ed. by L. S. Ruzer and N. H. Harley (CRC, Boca Raton, 2005), Chap. 13, p. 291.

19. S. Yang, G. W. M. Lee, C.-M. Chen, et al., J. Aerosol Med. 20, 484 (2007).

20. M. Jayaweeraa, H. Pererab, B. Gunawardanaa, and J. Manatungea, Environ. Res. 188, 109819 (2020). 
21. D. K. Milton, M. P. Fabian, B. J. Cowling, et al., PLoS Pathogens 9, 1003205 (2013).

22. A. P. Galvani, R. M. May, W. E. Bischoff, et al., J. Infect. Dis. 207, 1037 (2013).

23. W. E. Bischoff, K. Swett, I. Leng, and T. R. Peters, J. Infect. Dis. 207, 1037 (2013).

24. N. Doremalen, D. H. Morris, M. G. Holboork, et al., New Eng. J. Med. 382, 1564 (2020).

25. J. Gralton, E. Tovey, M.-L. McLaws, and W. D. Rawlinson, J. Infect. 62, 1 (2011).

26. J. W. Tang and G. S. Settles, New Eng. J. Med. 359 (15), 19 (2008).

27. M. Nicas, W. W. Nazaroff, and A. Hubbard, J. Occup. Environ. Hyg. 2, 143 (2005).

28. W. Yang and L. C. Marr, Appl. Environ. Microbiol. 78, 6781 (2012).

29. O. V. Pyankov, S. A. Bodnev, O. G. Pyankova, and I. E. Agranovski, J. Aerosol Sci. 115, 158 (2018).

30. W. C. Hinds, Aerosol Technology: Properties, Behavior, and Measurement of Airborne Particles (Wiley, Chichester, 1999).

31. D. Parienta, L. Morawska, G. R. Johnson, et al., J. Aerosol Sci. 42, 1 (2011).

32. L. Bourouiba, E. Dehandschoewercker, and J. W. M. Bush, J. Fluid Mech. 745, 537 (2014).

33. Z. Y. Han, W. G. Weng, and Q. Y. Huang, J. R. Soc. Interface 10, 1 (2013).

34. P. Reist, Introduction to Aerosol (Macmillan, 1984).

35. W. G. Lindsley, F. M. Blachere, R. E. Thewlis, et al., PLoS One 5, e15100 (2010).

36. P. Fabian, J. J. McDevitt, W. H. DeHaan, et al., PLoS One 3, e2691 (2008).

37. K. P. Fennelly, Lancet Respir. Med. 8, 914 (2020).

38. K. P. Fennelly, E. C. Jones-Lopez, I. Ayakaka, et al., Am. J. Respir. Crit. Care Med. 186, 450 (2012).

39. B. Patterson, C. Morrow, V. Singh, et al., Gates Open Res. 1, 11 (2018).

40. G. Theron, J. Limberis, R. Venter, et al., Nat. Med. (2020). https://doi.org/10.1038/s41591-020-0940-2

41. W. G. Lindsley, T. A. Pearce, J. B. Hudnall, et al., J. Occup. Environ. Hyg. 9, 443 (2012).

42. D. A. Edwards, J. C. Man, P. Brand, et al., Proc. Natl. Acad. Sci. U. S. A. 101, 17383 (2004).

43. N. H. L. Leung, D. K. W. Chu, E. Y. C. Shiu, et al., Nat. Med. 26, 676 (2020).

44. J. M. Macher, J. Douwes, P. Prezant, and T. Reponen, "Bioaerosols," in Aerosols Handbook: Measurements, Dosimetry, and Health Effects, 2nd ed., Ed. by L. S. Ruzer and N. H. Harley (CRC, Taylor and Francis Group, Boca Raton, 2013), Chap. 12, p. 285.

45. J. H. Seinfeld, Atmospheric Chemistry and Physics: From Air Pollution to Climate Change, 2nd ed. (Wiley, New York, 2006).

46. P. Fabian, J. Brain, E. A. Houseman, et al., J. Aerosol Med. Pulm. Drug Deliv. 24, 137 (2011).

47. A. K. Budyka and B. I. Ogorodnikov, Russ. J. Phys. Chem. A 73, 310 (1999).

48. A. K. Budyka and B. I. Ogorodnikov, Radiat. Biol. Radioecol. 35, 102 (1995).

NANOBIOTECHNOLOGY REPORTS Vol. 16 No. 1
49. B. I. Ogorodnikov, V. I. Skitovich, and A. K. Budyka, Rad. Biol. Radioekol. 38, 889 (1998).

50. B. I. Ogorodnikov and A. K. Budyka, At. Energy 91, 1016 (2001).

51. G. Lujaniene, B. I. Ogorodnikov, A. K. Budyka, et al., J. Environ. Radioactiv. 35, 71 (1997).

52. B. I. Ogorodnikov, A. K. Budyka, V. I. Skitovich, and A. V. Brodovoi, Izv., Atmos. Ocean. Phys. 32, 149 (1996).

53. W. G. Lindsley, W. P. King, R. E. Thewlis, et al., J. Occup. Environ. Hyg. 9, 681 (2012).

54. Highly Efficient Cleaning of Gases from Aerosols Using Petryanov Filters, Ed. by P. I. Basmanova (Nauka, Moscow, 2003) [in Russian].

55. E. A. Druzhinin, Production and Properties of Petryanov Filter Materials from Ultra-Thin Polymer Fibers (IzdAT, Moscow, 2007) [in Russian].

56. A. A. Kirsh, A. K. Budyka, and V. A. Kirsh, Ros. Khim. Zh. 52 (5), 97 (2008).

57. A. A. Kirsh and I. B. Stechkina, "The theory of aerosol filtration with fibrous filters," in Fundamentals of Aerosol Sciences, Ed. by D. T. Show (Wiley, New York, 1968), p. 165

58. A. K. Budyka and B. I. Ogorodnikov, in Aerosols Handbook: Measurements, Dosimetry and Health Effects, Ed. by L. S. Ruzer and N. H. Harley (CRC, Boca Raton, 2005), Chap. 17, p. 541.

59. A. K. Budyka and N. B. Borisov, Fiber Filters for Air Pollution Control (IzdAT, Moscow, 2008) [in Russian].

60. W. C. Hinds, Aerosol Technology (Wiley, New York, 1982).

61. A. A. Kirsh and V. A. Kirsh, Colloid. J. 81, 515 (2019).

62. W. S. Lyoo, J. H. Youk, S. W. Lee, and W. H. Park, Mater. Lett. 59, 3558 (2005).

63. S. O. Han, W. K. Son, J. H. Youk, et al., Mater. Lett. 59, 2998 (2005).

64. H. Hou and D. H. Reneker, Adv. Mater. 16, 69 (2004).

65. I. S. Chronakis, J. Mater. Proc. Technol. 167, 283 (2005).

66. A. A. Kirsh and V. A. Kirsh, Kolloid. Zh. 81 (6), 706 (2019).

67. A. K. Budyka, A. A. Kirsh, A. D. Shepelev, et al., "Scientific basis of production technology highly porous thin-layer membranes with a controlled nanostructure from continuous heat and chemically resistant polymer nanofibers by electrospinning," State Contract Report No. 02.513.11.3165 (Karpov Inst. Phys. Chem., Moscow, 2008).

68. C.-W. Kim, D.-S. Kim, S.-Y. Kang, et al., Polymer 47, 5097 (2006).

69. I. V. Petryanov, V. S. Koshcheev, P. I. Basmanov, et al., Lepestok. Lightweight Respirators (Nauka, Moscow, 2015) [in Russian].

70. D. H. Reneker and A. L. Yarin, Polymer 49, 2387 (2008).

71. S. Petrik and M. Maly, MRS Proc. 1240, 1 (2009). WW03

72. Y. Liu and J. H. He, Int. J. Nonlin. Sci. Num. 8, 393 (2007). 
73. SNC BEST ${ }^{\mathrm{TM}}$ Patented Electrospinning Technology, Stellenbosch Nanofiber Company. https://sncfibers.com/snc-best/.

74. L. Larrondo and R. St. John Manley, J. Polym. Sci.: Polym. Phys. Ed. 19, 909 (1981).

75. S. N. Malakhov and S. N. Chvalun, Fibre Chem. 49, 173 (2017).

76. Y. M. Li, X.-X. Wang, S.-X. Yu, et al., Polymers 10, 1246 (2018).

77. N. Ogata, G. Lu, T. Iwata, et al., J. Appl. Polym. Sci. 104, 1368 (2007).

78. J. Yoon, H.-S. Yang, B.-S. Lee, and W.-R. Yu, Adv. Mater. 30, 1704765 (2018).

79. C. Hacker, P. Jungbecker, G. Seide, et al., in 80 Years Department of Textiles: Proceedings International Conference on Latest Advances in High Tech Textiles and Textile-Based Materials, Het Pand, Ghent, Belgium, September 23-25, 2009, p. 71.

80. H. Li, H. Chen, X. Zhong, et al., J. Appl. Polym. Sci. 131, 40515 (2014).

81. Y. Weimin and L. Haoyi, IOP Conf. Ser.: Mater. Sci. Eng. 64, 012013 (2014).

82. J. G. McCulloch, Int. J. Nonwovens, No. 1, 1558925099OS-800123 (1999).

83. C. J. Ellison, A. Phatak, D. W. Giles, et al., Polymer 48, 3306 (2007).
84. S. J. Russell, Handbook of Nonwovens (Woodhead, Cambridge, 2006).

85. J. L. Daristotle, A. M. Behrens, A. D. Sandler, and P. Kofinas, ACS Appl. Mater. Interfaces 8, 34951 (2016).

86. M. R. Badrossamay, H. A. McIlwee, J. A. Goss, and K. K. Parker, Nano Lett. 10, 2257 (2010).

87. B. Raghavan, H. Soto, and K. Lozano, J. Eng. Fibers Fabrics 8, 52 (2013).

88. H. Peng, Y. Liu, and S. Ramakrishna, J. Appl. Polym. Sci. 134, 44578 (2017).

89. L. Zhaoa, L. Jianga, H. Lib, et al., Composites, Part B 153, 387 (2018).

90. Z. Song, J. Xie, J. Zhu, and J. Tao, J. Am. Acad. Dermatol., 30745 (2020).

91. W. W.-F. Leunga, C. W.-Y. Haua, and H.-F. Choya, Sep. Purif. Technol. 206, 26 (2018).

92. J. P. Feng, J. Wang, W. T. Hwang, and Y. M. Jo, J. Appl. Polym. Sci. 136, 48166 (2019).

93. Z. Cheng, J. Cao, L. Kang, et al., Mater. Lett. 221, 157 (2018).

94. M.-W. Kim, S. An, H. Seok, et al., ACS Appl. Mater. Interfaces 11, 26323 (2019).

95. H. L. Huang, D. M. Wang, and S. T. Kao, Sep. Purif. Technol. 54, 96 (2017).

Translated by D. Timchenko 